\title{
The Impact of Spatial Structure on Economic Efficiency of Beijing-Tianjin-Hebei Megalopolis in China
}

\author{
Xingling Huang, ${ }^{1}$ Guoping $\mathrm{Li}^{1}{ }^{1}$ and Jianguo Liu $\mathbb{D}^{2}$ \\ ${ }^{1}$ School of Government, Peking University, Beijing 100101, China \\ ${ }^{2}$ Tourism College, Beijing Union University, Beijing 100101, China \\ Correspondence should be addressed to Jianguo Liu; liujianguo009@163.com
}

Received 7 May 2020; Revised 6 June 2020; Accepted 22 June 2020; Published 27 July 2020

Guest Editor: Jun Yang

Copyright (C) 2020 Xingling Huang et al. This is an open access article distributed under the Creative Commons Attribution License, which permits unrestricted use, distribution, and reproduction in any medium, provided the original work is properly cited.

\begin{abstract}
This study constructs a theoretical model and empirical framework concerning how spatial structure affects economic efficiency using data on the Beijing-Tianjin-Hebei (BTH) megaregion between 2008 and 2017. The study finds the following: (1) the development of the internal spatial structure of the BTH urban agglomeration is unequal. The populations of most cities in the urban agglomeration are still in a dispersed state. Although urban populations have tended to agglomerate around multiple subcenter units in the cities, the trend towards population agglomeration around city centers is not found to be significant. (2) The total factor productivity (TFP) of the BTH urban agglomeration was not high in most years between 2008 and 2017, showing a fluctuating downward trend overall. The TFP of the urban agglomeration showed differential regional patterns. The decline of TFP growth in the BTH urban agglomeration is mainly due to declining technological progress, technological efficiency, and scale efficiency. Resource input remains the major driving force behind the development of the BTH megaregion. (3) Concerning how the spatial structure of the urban agglomeration affected economic efficiency, the study finds that primacy, urban Gini index, urban population size, human capital, informatization level, industrial structure, and science and technology levels have positive effects on economic efficiency, whereas dispersion, governmental role, economic openness, and land input have negative effects. This study has several policy implications. Achieving coordinated and integrated development of the BTH urban agglomeration will require constructing a scientific and regional spatial system, improving the development levels of regional central cities, divesting Beijing of noncapital functions, and reshaping the industrial layout of the BTH megaregion in an orderly manner, while continuously improving the internal hierarchical structure of urban agglomeration and strengthening intercity economic connections.
\end{abstract}

\section{Introduction}

Urban agglomeration has been the fastest growing regional type in the world since the mid- $20^{\text {th }}$ century, and the population and economic activities of most countries are now clustered around cities. By wielding their development advantages, urban agglomerations have secured their place in global economic development and have gradually become a new regional unit in global competition. Amid the rapid development of urban agglomerations, China's megaregions have developed into the world's largest urban agglomerations [1]. Particularly, the Beijing-Tianjin-Hebei (BTH) urban agglomeration with a land area of $7.24 \%$ has attracted
$2.35 \%$ of the population and produced 8.5 trillion in GDP, becoming a core economic region of Northern China. Despite the rapid economic development of the BTH urban agglomeration, there are still two major problems related to the area's growth. Firstly, the economic growth rate is not high. The economic aggregate of the BTH urban agglomeration is large, but the per capita GDP that reflects the level of regional economic development is far lower compared to the urban agglomerations of Yangtze River Delta and Pearl River Delta. Secondly, the core cities have no obvious driving effect on regional development. There are only two core cities in the region, with too many low-level cities and too few medium-sized cities. At the same time, urban diseases, 
such as population expansion, traffic congestion, and environmental degradation, have caused conflicts between population and economic growth, which have severely restricted the sustainable development of urban agglomerations and the ability to improve residents' quality of life. It is thus particularly important to explore how the evolution of various urban spatial structures have impacted economic efficiency in urban agglomerations. This will contribute to solving problems such as the significant difference in regional economic development of the BTH urban agglomeration compared to other regions as well as uncoordinated regional development, and problems in the process of coordinated development of the spatial structure and economic efficiency of the urban agglomeration and cities within the region.

\section{Literature Review}

This study performed searches on the China National Knowledge Infrastructure (CNKI) using the following keywords: "spatial structure" + "economic efficiency," "spatial structure" + "economic performance," "urban agglomeration" + "economic efficiency," "spatial structure" + "regional economy," "urban agglomeration" + "economic performance," "economic spatial structure," and "spatial structure" + "production efficiency." Searches were also performed on databases such as the Web of Science, SpringerLink, Elsevier, and EBSCO using the following terms: "spatial structure" + "economic efficiency," "urban agglomeration" + "economic efficiency," "spatial structure" + "production efficiency," "Metropolitan area" + "economic efficiency," and "Metropolitan area" + "spatial structure." The scope of the literature search was limited to SSCI/SCI and CSSCI/CSCD journals in related fields from China and abroad, and the publication period covered January 1, 1990, to December 31, 2019. More than 3,000 articles were obtained; these were narrowed down to around 1,000 key articles.

By using high-frequency keywords, we can find research hotspots that scholars pay attention to in each period, both inheritance and development. The research focuses on "spatial structure," "agglomeration economy," "Urban Agglomeration," and "production efficiency" (Table 1). The scale of the research shows the characteristics of "point, line, and area," including the city, city group, metropolitan area, economic belt, national, and other regions. The research methods demonstrate the trend of continuous scientific attempts, such as the gravitational model of night lighting data that are widely used. From the selected literature, the research content is quite rich which expands the research field. However, for integrity and coordination in the length of this study and the layout of the article, only research content closely related to the theme of the article is selected for sorting. The main research topics included the following.

2.1. Urban Space. From a macroperspective, the study of urban spatial structures investigates the location of cities in space and the scale and degree of spatial concentration,
TABLE 1: High-frequency keywords in the field of regional spatial structure and economic efficiency.

\begin{tabular}{lcc}
\hline Sequence number & Keywords & Frequency \\
\hline 1 & Urban space & 693 \\
2 & Urban spatial structure & 235 \\
3 & Spatial pattern & 156 \\
4 & Urban agglomerations & 148 \\
5 & Regional economies & 134 \\
6 & Economic efficiency & 127 \\
7 & Production efficiency & 119 \\
8 & Regional development & 105 \\
9 & China & 98 \\
10 & Agglomeration economy & 94 \\
11 & Influence factor & 90 \\
12 & Multicentric structure & 86 \\
13 & Industrial agglomeration & 81 \\
14 & Population agglomeration & 79 \\
15 & Internal contact & 76 \\
16 & Urbanization & 69 \\
17 & Dynamic mechanism & 67 \\
18 & Beijing-Tianjin-Hebei & 58 \\
19 & Spatial organization & 55 \\
20 & Space performance & 55 \\
\hline
\end{tabular}

which reflects urban interactions and interrelations, and analyzes the evolutionary trends of economic spatial patterns and intercity spatial connections and interactions [2-5]. Many studies have shown that the spatial economic patterns of urban agglomerations are affected by urban density, industrial agglomeration, and suburbanization [6-8]. It is argued that industrial agglomeration has promoted industrial relocation, which in turn has driven the migration of sociodemographic and economic industrial centers, thereby driving the evolution of regional spatial structures [9]. This industrial transfer has helped narrow the gaps between regional economies. Therefore, governments can directly influence the locations of enterprises and industries through infrastructure, financial subsidies, and other means [10]. From a microperspective, the study of urban space covers four main aspects: materials, economy, society, and ecology. It involves exploring the morphological characteristics of urban space, urban functional structure, urban functional connections, and urban spatial configuration. Land use is at the core of urban spatial organization and is also the focus of research on material spatial structure. Investigating the assessment of urban intensive land use as well as spatial pattern evolution and its transformation can help to improve land use efficiency and address structural imbalances in land use [11-14]. Other scholars argue that a polycentric spatial structure is an efficient model of agglomeration for megacities, whereas a monocentric spatial structure has higher labor productivity for cities within the limits of the megacity [15].

2.2. Development of Urban Agglomerations. Amid continuous changes in the global competitive landscape and the deepening of the international division of labor, urban agglomerations are a completely new regional unit and have become a main feature of global urbanization in the $21^{\text {st }}$ 
century; they will determine the new pattern of the global economy $[16,17]$. The spatial structure of urban agglomerations has become a research hotspot. Most urban agglomeration research explores urban agglomeration structures [18]; spatial pattern evolution [9, 19]; the integration of urban agglomerations [20]; the identification [21] and spatial reconstruction [22] of urban agglomerations; the classification of grades and types [23]; and effects on economic efficiency. Scholars have mainly used nighttime light data, modelling, satellite remote sensing, geographic information systems (GIS), and other methods [24-26] as research methods to study the spatiotemporal evolution of population distribution, industrial structure, land use, and other aspects of urban agglomerations [17, 26-28]. Many scholars have sought to determine which spatial structure should be adopted to promote the sustainable development of urban agglomerations. The classical theory of agglomeration economies was the first to explain the spatial pattern of economies. It posited that a monocentric spatial pattern could promote improvements in economic efficiency [29]. However, due to the presence of geospatial distance, scholars began questioning the use of agglomeration economies to explain the effects of spatial structure on economic efficiency and subsequently proposed concepts such as "urban network externalities" [30], "regional externalities" [31], and "borrowed size" [32] to examine the relationship between geospatial patterns and economic performance. Alonso posited that the agglomeration of industries and populations in smaller cities can prevent the negative externalities of larger cities while also achieving the latter's external economies of scale [33]. Other studies have also shown that the negative transaction costs of population and industrial agglomeration in urban agglomerations will gradually exceed the benefits generated by their economies of scale. This will ultimately lead to their transformation from a monocentric to a polycentric spatial structure, which is more conducive to the improvement of economic efficiency [34-36]. However, due to the influence of heterogeneous factors such as city size and development stage, the polycentric spatial structure will lead to unequal economic performance.

\subsection{Economic Efficiency of Urban Agglomerations.} Scholars have been conducting extensive research on productivity since the $\mathrm{C}-\mathrm{D}$ production function was proposed by Cobb and Douglas in the early $20^{\text {th }}$ century. Studying growth in economic output, Abramovitz found that, in addition to the growth in the input of production factors, nonproduction factors can also promote economic growth [37]. Solow attributed this finding, which is also known as the "Solow residual" (or "total factor productivity"), to technological progress. Several subsequent papers explored the concepts of economic efficiency and total factor productivity (TFP) in more detail and depth [38, 39]. Studies used methods such as data envelopment analysis to carry out empirical analyses of regional economic efficiency and infrastructure investment efficiency at different spatial scales and to explore their spatial evolutionary trends and other differential factors [40, 41]. Studies have found the following: there is significant growth in the economic performance of cities, and urban economic efficiency is intricately linked with city level $[42,43]$; technological progress is the main driver of regional TFP [44]; the monocentric structure is conducive to the improvement of economic efficiency $[45,46]$; and the spatial structure of urban agglomerations has generally shown an evolutionary trend towards monocentricism [33]. On smaller geographic scales such as within cities and megaregional limits, however, the monocentric spatial structure can also promote the improvement of a city's economic efficiency [34], and this facilitative effect is especially prominent in smaller urban agglomerations [47]. Studies have also shown that the populations in urban agglomerations exhibit a polycentric distribution and that the monocentric distribution of their industries is also conducive to improving economic performance [48]. However, the monocentric structure of cities can also hinder provincial economy [49]. Although many sectors show more intense economic activity in monocentric metropolitan areas, these sectors tend to show greater productivity in polycentric metropolitan areas because the spatial range of agglomeration advantages has been regionalized, whereas agglomeration diseconomies remain more limited to the local level [50].

A review of the research suggests that scholars have conducted ample research into urban space, agglomerations, and efficiency but that research on the impact of spatial structure on economic efficiency is lacking. Therefore, this paper mainly focuses on the impact of the evolution of the urban spatial structure of China's megalopolis (Beijing, Tianjin, and Hebei) on regional economic efficiency. The study aims to consider the change in urban spatial structure of the BTH urban agglomeration as a link to regional economic efficiency and to deeply explore the significant impact of regional spatial structure evolution on regional economic efficiency. Based on previous research results regarding the economic growth theory and spatial structure theory, the spatial structure and economic efficiency of urban agglomerations are linked by the establishment of a regression model. In addition, this study analyzes whether the regional spatial structure of megaregions can affect their economic efficiency, investigates the extent of this impact, and examines how regional economic efficiency can be improved by optimizing the regional spatial structure of megaregions. By addressing these issues, we hope to lay a theoretical foundation for policies designed to optimize the spatial structure and efficiency of China's megaregions.

\section{Methods, Data, and Study Area}

3.1. Study Area. The Beijing-Tianjin-Hebei (BTH) urban agglomeration (Figure 1), which includes Beijing, Tianjin, and eleven cities in Hebei Province, can be described as a "world-class urban agglomeration with the capital as its core, a regional coordinated development and reform guidance area, a new engine for national innovation-driven economic growth, and an ecological restoration and environmental improvement demonstration zone." Statistical data indicate that the BTH urban agglomeration covers a land area of 


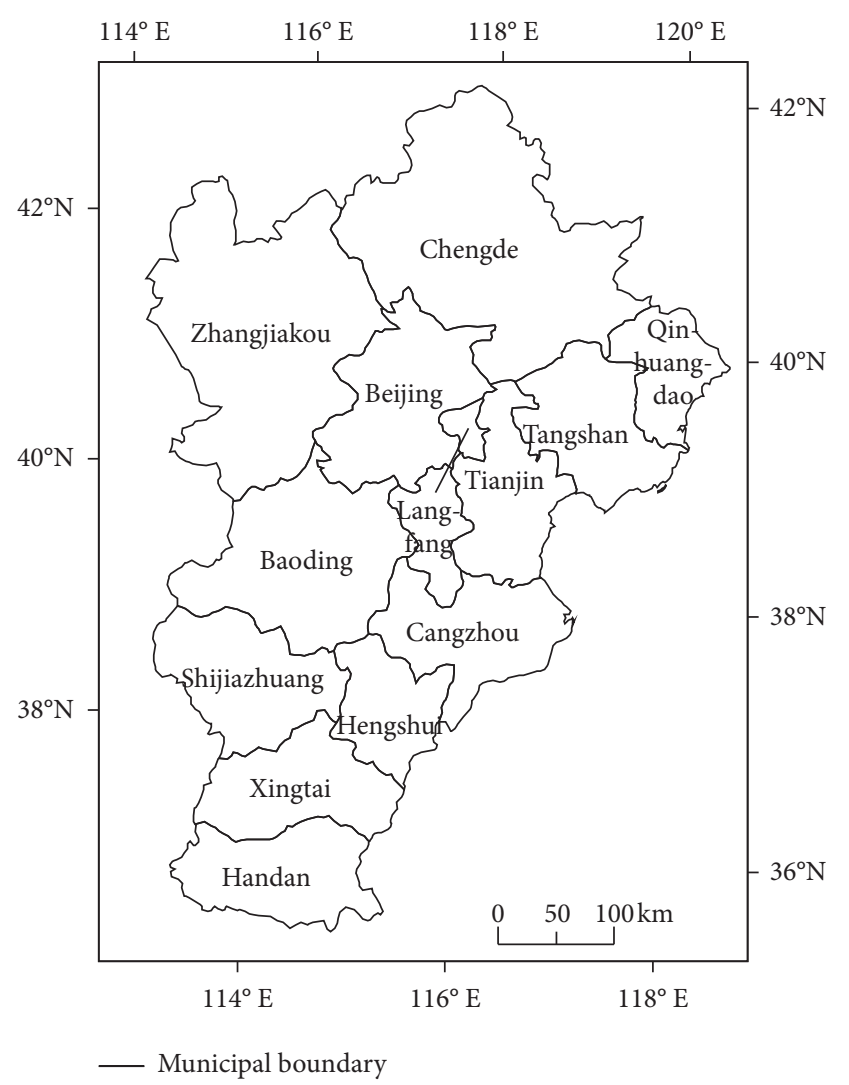

FIGURE 1: Study area.

about $120,000 \mathrm{~km}^{2}$ with a total population of more than 110 million. In 2018, its combined GDP exceeded RMB 8.5 trillion. The ratio of the three industry levels in the BTH region is $4.3: 34.4: 61.3$, of which tertiary industries account for $81 \%$ in Beijing, $58.6 \%$ in Tianjin, and $46.2 \%$ in Hebei (National Bureau of Statistics of China, 2019). In November 2018, the "Opinions of the CPC Central Committee and the State Council on Establishing More Effective New Coordinated Regional Development Mechanisms" stated that, to achieve the key goal of divesting Beijing of its noncapital functions, the coordinated development of Beijing, Tianjin, and Hebei shall be promoted; the regional economic structure and spatial structure shall be adjusted; the construction of Xiong'an New District in Hebei and Beijing city subcenters shall be boosted; and an optimal development approach wherein megacities, supercities, and other populous areas are divested of some of their functions in an orderly manner and urban diseases that are effectively treated shall be explored.

\subsection{Calculation Methods}

3.2.1. Measurement Methods of Spatial Structure. The quantitative measurement of an urban spatial structure is a prerequisite for understanding its characteristics. The main indicators for measuring the degree of concentration-dispersion in urban agglomerations include the Gini coefficient, $E G$ index, increment index, weighted distance index, and dispersion coefficient. Most studies have used the "agglomeration-dispersion," "monocentric-polycentric," "tight-loose," and "gap-equality" dimensions to measure regional spatial structural characteristics. In this study, four variables were used to measure urban spatial structure: primacy, dispersion, urban Gini coefficient, and city size index. These are detailed below.

(1) Primacy index. Primacy is a common indicator used to measure cities along the monocentric-polycentric dimension. It characterizes the distribution of the city's internal resources in the largest spatial unit and other spatial units. The two-city index was selected as a measure of primacy. It is given by the following equation:

$$
S=\frac{P 1}{P 2} \text {. }
$$

In equation (1), $P_{i}$ denotes the population size of the $i^{\text {th }}$ spatial unit, and $S$ is the degree of primacy. According to the rank-size rule, the ideal value of the two-city index is 2 . A higher degree of primacy implies that the urban spatial structure has a greater tendency towards monocentricism, whereas the opposite implies a greater tendency towards a polycentric structure.

(2) Dispersion. Agglomeration and dispersion are the basic forms of movement in urban areas. The academic community considers agglomeration-dispersion to be the internal driving force behind the formation and evolution of regional spatial structures. Dispersion will cause the loss of externalities in urban agglomeration economies, which will have negative effects on the optimization of urban functions, whereas agglomeration can promote the improvement of urban functions due to its spillover effects. The agglomeration-dispersion coefficient is generally used to reflect the degree of agglomeration among the populations in the city centers of urban agglomerations. Dispersion was selected as an indicator to characterize the dimension of urban "agglomeration-dispersion," and is given by the following equation:

$$
D_{i}=1-\sum \frac{S_{i}}{S}
$$

In equation (2), $D_{i}$ denotes the degree of dispersion, $S$ denotes the size of the resident population in city $i$, and $S_{i}$ denotes the size of the resident population in the municipal districts. A higher value of dispersion implies that the population is more dispersed in the city and does not have a clear central regional unit; a lower value of dispersion implies that the population is more concentrated in the city.

(3) Urban Gini index. The urban Gini coefficient is an indicator measuring urban agglomeration in the "gapequality" dimension, reflecting the degree of population concentration in the urban system. This study draws on the methods proposed by Marshall to measure the degree of equalization in the population distribution of the urban system. The equation for the Gini index is given as follows:

$$
\text { Gini }=\frac{T}{2 S(n-1)},
$$

where $T$ denotes the sum of the absolute values of the differences in population size between $n$ spatial units in the 
city and $S$ denotes the total population of the city. The closer the Gini index is to 0 , the more dispersed the population. A Gini index greater than 0.6 implies that city size is extremely unequally distributed [51]. The closer the Gini index to 1 , the more concentrated the urban population and the more concentrated the distribution of city size.

(4) City size. City size refers to the population size, economic size, and spatial size as reflected in the population, resources, commodities, buildings, and other factors within a certain urban region; these are the three most important forms constituting city size. Although the concept of urban agglomeration size involves the three aspects of population size, total economic volume, and geographical area, population size can also determine economic and spatial size to a certain extent, while market size as reflected in population size shows a U-shaped relationship with economic growth [52]. Therefore, population size is often used to quantify urban agglomeration models. In this study, the total resident population in the city's municipal districts is used as an indicator to characterize city size in order to describe the degree of population and economic agglomeration within the city.

\subsubsection{Measurement Methods of Total Factor Productivity} (TFP). (1) DEA-Malmquist index. The nonparametric Malmquist index in DEA was used to measure the spatial differentiation of economic efficiency and TFP in the BTH urban agglomeration. The advantage of the Malmquist index is that it does not require any specific function forms or distribution assumptions, and the frontier production function can be obtained using only linear programming computations $[53,54]$. The productivity index model is given in the following equation:

$$
M_{0}\left(x_{t}, y_{t}, x_{t+1}, y_{t+1}\right)=\sqrt{\frac{d_{0}^{t}\left(x_{t+1}, y_{t+1}\right)}{d_{0}^{t}\left(x_{t}, y_{t}\right)} \times \frac{d_{0}^{t+1}\left(x_{t+1}, y_{t+1}\right)}{d_{0}^{t+1}\left(x_{t}, y_{t}\right)}} .
$$

Equation (4) represents the TFP changes from the base period to period $t$. The Malmquist index of productivity change can also be decomposed into the indices of technical efficiency change (EC) and technical change (TC) from base period $t$ to period $t+1$ :

$$
M_{0}\left(x_{t}, y_{t}, x_{t+1}, y_{t+1}\right)=\frac{d_{0}^{t}\left(x_{t+1}, y_{t+1}\right)}{d_{0}^{t}\left(x_{t}, y_{t}\right)} \sqrt{\frac{d_{0}^{t}\left(x_{t+1}, y_{t+1}\right)}{d_{0}^{t+1}\left(x_{t+1}, y_{t+1}\right)} \times \frac{d_{0}^{t}\left(x_{t}, y_{t}\right)}{d_{0}^{t+1}\left(x_{t}, y_{t}\right)}} .
$$

In equation (5), technical efficiency change (EC) can be further decomposed into pure technical efficiency change (PTEC) and scale efficiency change (SEC) from the base period $t$ to period $t+1$ (i.e., the formula for TFP can be expressed as TFP $=\mathrm{TC} \times \mathrm{PTEC} \times \mathrm{SEC}$ ). Technical efficiency measures the maximum output capacity achieved by the current production level. Scale efficiency refers to whether the input-output ratio of the economic unit is reasonable and can maximize the output. Pure technical efficiency measures the degree of effectiveness by which the economic unit can maximize output under existing conditions of production technology. All these values can be greater than, equal to, or less than 1, indicating improvement, no change, or reduced efficiency, respectively.

(2) Indicator selection. The fixed capital stock and labor force of Beijing, Tianjin, and Hebei were chosen as the input factors, and regional GDP was chosen as the output factor; the three factors together constitute the input-output indicators. The data sources and processing methods for each variable are as follows. Labor force $(L)$ was expressed using the total number of employed persons across all sectors in the municipal districts of Beijing, Tianjin, and Hebei. Employed persons comprised all individuals who had a certain level of capacity for work, were engaged in some kind of work, and earned a specific level of income. Fixed capital stock $(K)$ was based on Keller's method of calculating physical capital stock using the equation $K_{0}=I_{0} /(g+\delta)$, where $I_{0}, g$, and $\delta$ denote the investment volume of the first year, average investment growth rate, and the capital depreciation rate, respectively ( $\delta$ was set to $9.6 \%$ ). Then, the fixed investment price index was used with 2007 as the base period to calculate the original price of fixed capital over the years. Finally, the "perpetual inventory method" was used to calculate the physical capital stock of the corresponding year, as given by the following formula:

$$
K_{i t}=(1-\delta) K_{i t-1}+I_{i t}, \quad(t=1,2,3, \ldots, t-1, t) .
$$

In equation (6), $K_{i t}$ and $K_{i t-1}$ denote the fixed capital stock in years $t$ and $t-1$, respectively, and $I_{i t}$ is the total investment in fixed assets of the whole of society smoothed by the fixed capital investment deflator at the constant price of the base period for the $i^{\text {th }}$ city in year $t$. The base period used was 2007, and the fixed capital stock of the base period was obtained by dividing the total fixed assets of the whole society by $10 \%$. The fixed asset investment deflator was calculated using the fixed asset investment price index of each city over the years. The GDP of the regional output variable was obtained by smoothing using the GDP deflators of each year for the 13 cities in the BTH urban agglomeration, with 2007 as the base period.

3.3. Data. All variable data used in this study were drawn from the 2008-2018 Beijing Statistical Yearbook [55], Beijing Area Statistical Yearbook [56], Hebei Statistical Yearbook [57], Tianjin Statistical Yearbook [58], China City Statistical Yearbook [59], China Statistical Yearbook (County-Level) [60], the statistical yearbooks of the counties and cities studied, and the China Economic Information Network database and the statistical communiqués on national economic and social development of the years under study. Due to problems such as statistical definition issues, some cities had missing data for individual years, which were completed via linear interpolation. A total of 13 spatial units were specified for the BTH urban agglomeration, which consisted of Beijing municipality, Tianjin municipality, and 11 prefecture-level cities in Hebei Province (Shijiazhuang, Tangshan, Qinhuangdao, Handan, Xingtai, Baoding, Zhangjiakou, Chengde, Cangzhou, Langfang, and Hengshui). Grouping "municipalities" and "prefecture-level 
cities" together at the same level for analysis was necessary due to the data availability of this spatial structure study because, while data from the cities' second-level spatial units were needed to measure primacy, dispersion, and other indicators of the regional units, data for the towns and subdistricts of Beijing and Tianjin were incomplete, which made it difficult to accurately reflect the spatial structure of the urban areas. Hence, Beijing and Tianjin were analyzed as single research units, whereas Hebei Province was divided into 11 prefecture-level cities.

\section{Results and Analysis}

\subsection{Measurement Results and Analysis of BTH Urban Agglomeration Spatial Structure}

4.1.1. Measurement Results and Analysis of Primacy. The primacy of the BTH urban agglomeration was calculated for 2008-2017 using the two-city index method. Differences were found in the spatial variation of primacy among the various cities in Beijing, Tianjin, and Hebei. The maximum and minimum standard deviations (SDs) appeared in 2005 (0.390) and 2009 (0.337), and the statistical dispersion among cities was relatively large. Tianjin ranked highest in terms of primacy, with values ranging between 2.0 and 2.5, which were close to the ideal primacy value of 2 (Table 2). This result indicates that Tianjin's spatial structure is relatively reasonable, with a rational distribution of resource factors within the city, a good capacity for coordinated development, and strong comprehensive competitiveness.

However, Tianjin has shown a rising trend in its primacy over the past 10 years, which implies that it should be vigilant in preventing conflicts between the people, economy, and environment caused by the excessive population and industrial agglomeration. The primacy value of Beijing remained at around 1, indicating that it already has the polycentric, networked spatial structure of a megacity. By comparison, the primacy values of the various cities in Hebei Province were relatively similar to those of Beijing. The primacy coefficient values ranged between 1 and 1.6, indicating that these cities did not have a clear monocentric spatial structure. Among them, Chengde had the lowest degree of primacy in 2009 (1.000), Hengshui had the lowest in 2011 and 2015 (1.002), Langfang had the lowest in 2013 (1.027), and Handan had the lowest in 2017 (1.003). The primacy values of Beijing, Shijiazhuang, Tangshan, Baoding, Langfang, and Hengshui were also relatively low, all below 1.1. The results show that the average primacy value of the BTH urban agglomeration has been continuously increasing. This implies that the unequal population and resource allocation within the urban agglomeration is worsening, while some cities are evolving towards a weakly monocentric spatial structure. A polycentric spatial structure is more suitable for spatial units at the level of megacities or supercities; for lower-level cities, however, a polycentric structure may restrict population, industrial, and economic aggregation, which is not conducive to urban economic development.
4.1.2. Measurement Results and Analysis of Dispersion. As shown in Table 3, the dispersion of most cities in the BTH urban agglomeration is increasing, which indicates that the population has exhibited a tendency towards agglomerating in one or more secondary units within the city. The SD of the dispersion values in the BTH urban agglomeration indicates that the differences in the dispersion spatial structure were relatively small among the cities. The average value of the dispersion in the spatial structure of the urban agglomeration increased from 0.703 in 2008 to 0.729 in 2017; hence, the spatial structure of the urban agglomeration did not show a significant trend of concentrating around central regions.

4.1.3. Measurement Results and Analysis of Urban Gini Index. The results of Table 4 reveal fluctuations in the differences among the Gini coefficients within the BTH agglomeration in general; the average value decreased from 0.271 in 2009 to 0.252 in 2017 . This indicates that the polarization effect on the population size in the BTH urban agglomeration was not significant and that the agglomeration remained in a dispersed state. The data show that the Gini coefficients of the urban agglomeration generally ranged between 0.051 and 0.533 , indicating large differences in the degree of population agglomeration among the cities and thus a significant gap in city size. This result may have occurred because the BTH megaregion has undergone rapid development since the 1990s, but economic growth among the cities in this megaregion has been unequal due to the spillover effects of the Beijing and Tianjin economies and the poverty zone surrounding the megaregion. This has led to significant differences in coordination between urban population growth and economic growth [61].

4.2. Results and Analysis of TFP in the BTH Metropolitan. The TFP of the BTH urban agglomeration was measured using DEAP 2.1. The results indicate that the TFP of the BTH urban agglomeration was relatively low from 2008 to 2017 and showed a decreasing trend (Figure 2). The average TFP values of Beijing, Tianjin, and Langfang were significantly higher than the average TFP level of the overall urban agglomeration. The TFP growth rate of the urban agglomeration was negative for all years, except for 2016 and 2017. The TFP of the BTH urban agglomeration showed the fastest decline in $2008(-36.71 \%), 2009(-17.69 \%)$, and 2010. During this period, Beijing and Tianjin showed positive growth rates for most years. Xingtai, Baoding, Zhangjiakou, Chengde, Cangzhou, Langfang, and Hengshui showed increased growth rates in 2016 and 2017, whereas TFP growth in the other cities declined in most years (Table 5).

To further analyze the changes in the TFP of the BTH urban agglomeration and its efficiency composition, this study calculated the TC, EC, PTEC, SEC, and Malmquist productivity indices for the years under examination. As Table 6 shows, from 2008 to 2017, EC decreased by 7.2\%, TC and SEC decreased by $0.3 \%$ and $0.2 \%$, respectively, and PTEC remained unchanged. In 2008-2009, there was a significant decrease in the EC of the BTH urban 
TABLE 2: Calculation results of the primacy of Beijing-Tianjin-Hebei urban agglomeration.

\begin{tabular}{|c|c|c|c|c|c|c|c|c|c|c|c|}
\hline Cities & 2008 & 2009 & 2010 & 2011 & 2012 & 2013 & 2014 & 2015 & 2016 & 2017 & Mean \\
\hline Beijing & 1.052 & 1.031 & 1.080 & 1.075 & 1.075 & 1.074 & 1.066 & 1.071 & 1.073 & 1.074 & 1.067 \\
\hline Tianjin & 2.066 & 2.276 & 2.437 & 2.403 & 2.394 & 2.444 & 2.476 & 2.515 & 2.496 & 2.496 & 2.400 \\
\hline Shijiazhuang & 1.039 & 1.043 & 1.031 & 1.025 & 1.041 & 1.197 & 1.038 & 1.038 & 1.033 & 1.026 & 1.051 \\
\hline Tangshan & 1.061 & 1.063 & 1.057 & 1.059 & 1.063 & 1.066 & 1.065 & 1.064 & 1.061 & 1.068 & 1.063 \\
\hline Qinhuangdao & 1.423 & 1.424 & 1.368 & 1.368 & 1.364 & 1.363 & 1.388 & 1.432 & 1.462 & 1.521 & 1.411 \\
\hline Handan & 1.103 & 1.107 & 1.102 & 1.071 & 1.039 & 1.151 & 1.097 & 1.097 & 1.003 & 1.003 & 1.077 \\
\hline Xingtai & 1.253 & 1.291 & 1.305 & 1.309 & 1.299 & 1.294 & 1.298 & 1.298 & 1.298 & 1.100 & 1.275 \\
\hline Baoding & 1.017 & 1.010 & 1.005 & 1.003 & 1.001 & 1.090 & 1.105 & 1.090 & 1.090 & 1.091 & 1.050 \\
\hline Zhangjiakou & 1.077 & 1.052 & 1.110 & 1.186 & 1.274 & 1.170 & 1.170 & 1.170 & 1.142 & 1.243 & 1.159 \\
\hline Chengde & 1.001 & 1.000 & 1.052 & 1.041 & 1.034 & 0.945 & 1.027 & 1.027 & 1.026 & 1.237 & 1.039 \\
\hline Cangzhou & 1.089 & 1.067 & 1.065 & 1.064 & 1.010 & 1.076 & 1.112 & 1.119 & 1.088 & 1.172 & 1.086 \\
\hline Langfang & 1.052 & 1.035 & 1.029 & 1.027 & 1.027 & 1.027 & 1.029 & 1.019 & 1.026 & 1.016 & 1.029 \\
\hline Hengshui & 1.001 & 1.004 & 1.002 & 1.002 & 1.003 & 1.004 & 1.021 & 1.001 & 1.020 & 1.020 & 1.008 \\
\hline $\mathrm{SD}$ & 0.282 & 0.337 & 0.372 & 0.364 & 0.364 & 0.369 & 0.377 & 0.390 & 0.390 & 0.388 & 0.363 \\
\hline Max & 2.066 & 2.276 & 2.437 & 2.403 & 2.394 & 2.444 & 2.476 & 2.515 & 2.496 & 2.496 & 2.400 \\
\hline Min & 1.001 & 1.000 & 1.002 & 1.002 & 1.001 & 0.945 & 1.021 & 1.001 & 1.003 & 1.003 & 0.998 \\
\hline Mean & 1.172 & 1.185 & 1.203 & 1.203 & 1.202 & 1.223 & 1.223 & 1.226 & 1.217 & 1.236 & 1.209 \\
\hline
\end{tabular}

TAвLE 3: Results of dispersion degree of Beijing-Tianjin-Hebei Metropolitan (2008-2017).

\begin{tabular}{llllllllllll}
\hline Cities & 2008 & 2009 & 2010 & 2011 & 2012 & 2013 & 2014 & 2015 & 2016 & 2017 & Mean \\
\hline Beijing & 0.405 & 0.405 & 0.403 & 0.405 & 0.407 & 0.628 & 0.628 & 0.629 & 0.635 & 0.642 & 0.519 \\
Tianjin & 0.672 & 0.686 & 0.689 & 0.699 & 0.715 & 0.667 & 0.667 & 0.684 & 0.685 & 0.685 & 0.685 \\
Shijiazhuang & 0.552 & 0.557 & 0.559 & 0.560 & 0.544 & 0.681 & 0.581 & 0.578 & 0.576 & 0.577 & 0.577 \\
Tangshan & 0.589 & 0.586 & 0.587 & 0.587 & 0.587 & 0.585 & 0.584 & 0.584 & 0.582 & 0.584 & 0.586 \\
Qinhuangdao & 0.514 & 0.514 & 0.519 & 0.520 & 0.519 & 0.520 & 0.517 & 0.510 & 0.512 & 0.549 & 0.519 \\
Handan & 0.666 & 0.664 & 0.664 & 0.665 & 0.667 & 0.661 & 0.660 & 0.660 & 0.678 & 0.678 & 0.666 \\
Xingtai & 0.903 & 0.905 & 0.906 & 0.906 & 0.905 & 0.909 & 0.900 & 0.900 & 0.898 & 0.900 & 0.903 \\
Baoding & 0.734 & 0.733 & 0.736 & 0.736 & 0.736 & 0.726 & 0.724 & 0.726 & 0.726 & 0.726 & 0.730 \\
Zhangjiakou & 0.708 & 0.709 & 0.710 & 0.712 & 0.720 & 0.713 & 0.713 & 0.713 & 0.708 & 0.735 & 0.714 \\
Chengde & 0.850 & 0.843 & 0.817 & 0.816 & 0.815 & 0.815 & 0.814 & 0.814 & 0.814 & 0.867 & 0.827 \\
Cangzhou & 0.887 & 0.886 & 0.887 & 0.886 & 0.881 & 0.883 & 0.888 & 0.887 & 0.886 & 0.884 & 0.886 \\
Langfang & 0.852 & 0.856 & 0.856 & 0.856 & 0.857 & 0.857 & 0.854 & 0.853 & 0.852 & 0.852 & 0.855 \\
Hengshui & 0.809 & 0.809 & 0.810 & 0.810 & 0.809 & 0.809 & 0.809 & 0.808 & 0.807 & 0.798 & 0.808 \\
SD & 0.134 & 0.134 & 0.132 & 0.132 & 0.132 & 0.102 & 0.107 & 0.107 & 0.106 & 0.105 & 0.119 \\
Max & 0.903 & 0.905 & 0.906 & 0.906 & 0.905 & 0.909 & 0.900 & 0.900 & 0.898 & 0.900 & 0.903 \\
Min & 0.405 & 0.405 & 0.403 & 0.405 & 0.407 & 0.520 & 0.517 & 0.510 & 0.512 & 0.549 & 0.463 \\
Mean & 0.703 & 0.704 & 0.703 & 0.704 & 0.705 & 0.727 & 0.718 & 0.719 & 0.720 & 0.729 & 0.713 \\
\hline
\end{tabular}

agglomeration, possibly due to the international financial crises triggered by the 2008 US subprime mortgage crisis. After 2009, the magnitude of the decline in EC decreased each year. In 2008, facing a foreign economic crisis, the Chinese government implemented a series of major measures, including RMB 4 trillion worth of investments. The data also suggest that, from 2014 to 2017, the TFP of the BTH urban agglomeration and its four components showed varying degrees of improvement, perhaps due to the measures implemented by the government. In 2015, the Chinese government proposed the "Coordinated Development of Beijing-Tianjin-Hebei" to promote the transportation and market integration of Beijing, Tianjin, and Hebei. This policy strongly encouraged the coordinated development of the Beijing, Tianjin, and Hebei economies. Our findings also indicate that government-led investments have been the source of and driving force behind economic growth in the BTH megaregion, whereas technological progress characterized by innovation has not been fully utilized in economic growth [62].

\section{Analysis of Effects of Spatial Structure on Economic Efficiency}

A spatial structure is the distribution patterns of population and economic activities across geographical space. During its evolution, a spatial structure is observed mainly in the forms of monocentricism-polycentricism and agglomeration-dispersion. The economic efficiency of the region is an important criterion for judging the advantages and disadvantages of spatial structure. To examine how spatial structure changes in the BTH urban agglomeration have affected economic efficiency, we established several theoretical hypotheses and constructed a theoretical model, and then performed model testing and analysis. 
TABLE 4: Results of Gini coefficient of urban scale of Beijing-Tianjin-Hebei Metropolitan (2008-2017).

\begin{tabular}{llllllllllll}
\hline Cities & 2008 & 2009 & 2010 & 2011 & 2012 & 2013 & 2014 & 2015 & 2016 & 2017 & Mean \\
\hline Beijing & 0.528 & 0.530 & 0.527 & 0.530 & 0.528 & 0.532 & 0.533 & 0.533 & 0.527 & 0.519 & 0.529 \\
Tianjin & 0.371 & 0.369 & 0.349 & 0.358 & 0.354 & 0.358 & 0.359 & 0.356 & 0.356 & 0.357 & 0.359 \\
Shijiazhuang & 0.340 & 0.338 & 0.337 & 0.336 & 0.358 & 0.365 & 0.338 & 0.340 & 0.341 & 0.340 & 0.343 \\
Tangshan & 0.276 & 0.279 & 0.281 & 0.281 & 0.281 & 0.280 & 0.281 & 0.281 & 0.277 & 0.277 & 0.279 \\
Qinhuangdao & 0.285 & 0.285 & 0.281 & 0.280 & 0.280 & 0.256 & 0.257 & 0.260 & 0.257 & 0.275 & 0.272 \\
Handan & 0.337 & 0.334 & 0.333 & 0.330 & 0.330 & 0.336 & 0.329 & 0.329 & 0.311 & 0.310 & 0.328 \\
Xingtai & 0.181 & 0.180 & 0.181 & 0.182 & 0.182 & 0.180 & 0.183 & 0.184 & 0.184 & 0.181 & 0.182 \\
Baoding & 0.332 & 0.332 & 0.332 & 0.333 & 0.333 & 0.377 & 0.378 & 0.376 & 0.376 & 0.376 & 0.355 \\
Zhangjiakou & 0.265 & 0.265 & 0.256 & 0.258 & 0.253 & 0.285 & 0.285 & 0.284 & 0.274 & 0.252 & 0.268 \\
Chengde & 0.244 & 0.244 & 0.257 & 0.258 & 0.258 & 0.054 & 0.054 & 0.054 & 0.054 & 0.051 & 0.153 \\
Cangzhou & 0.147 & 0.148 & 0.147 & 0.146 & 0.148 & 0.155 & 0.150 & 0.154 & 0.149 & 0.145 & 0.149 \\
Langfang & 0.111 & 0.109 & 0.113 & 0.114 & 0.115 & 0.114 & 0.116 & 0.115 & 0.113 & 0.114 & 0.113 \\
Hengshui & 0.109 & 0.110 & 0.110 & 0.110 & 0.110 & 0.109 & 0.107 & 0.109 & 0.109 & 0.082 & 0.107 \\
SD & 0.113 & 0.113 & 0.110 & 0.111 & 0.111 & 0.130 & 0.129 & 0.128 & 0.127 & 0.129 & 0.120 \\
Max & 0.528 & 0.530 & 0.527 & 0.530 & 0.528 & 0.532 & 0.533 & 0.533 & 0.527 & 0.519 & 0.529 \\
Min & 0.109 & 0.109 & 0.110 & 0.110 & 0.110 & 0.054 & 0.054 & 0.109 & 0.054 & 0.051 & 0.087 \\
Mean & 0.271 & 0.271 & 0.270 & 0.270 & 0.272 & 0.262 & 0.259 & 0.259 & 0.256 & 0.252 & 0.264 \\
\hline
\end{tabular}

\subsection{Theoretical Hypotheses and Variables}

5.1.1. Basic Hypotheses. This study proposes the following hypotheses:

$\mathrm{H}_{1}$ : the monocentric spatial structure has a positive effect on economic efficiency because a monocentric structure has stronger resource uptake and control capabilities, which is more conducive to the improvement of productivity.

$\mathrm{H}_{2}$ : the agglomeration of space has a significantly positive effect on the growth of TFP. The agglomeration of China's urban agglomerations is increasing overall, while the relationship between its economic agglomeration and economic growth conforms to the characteristics of the inverted-U hypothesis [63].

$\mathrm{H}_{3}$ : urban population size significantly promotes the growth of TFP. As a crucial core area of the Northern Chinese economy, BTH urban agglomeration has attracted a large number of people, while the technological knowledge and human capital effects brought about by such population agglomeration can significantly enhance the economic efficiency of the urban agglomeration.

$\mathrm{H}_{4}$ : primacy has a positive effect on TFP. Urban primacy represents not only the strength and position of the city in its region but also the city's capacity for agglomerating production factors. It is generally understood that a city with higher primacy will have a greater capacity for agglomerating human and financial capital, as well as a stronger capacity for improving its own economic efficiency and a greater radiating effect, driving the economic development of surrounding cities.

5.1.2. Selection of Control Variables. The following control variables were specified based on a collation of relevant papers, combined with an analysis of the data and the factors influencing economic efficiency: human capital, informatization level, industrial structure, land input, economic openness, governmental role, and technological level.
The effect of human capital (Hum) on economic efficiency is reflected mainly in the knowledge accumulated by the human capital itself, which can promote economic efficiency by fostering improvements in productivity and the formation of production factors [64]. This study used the number of students still studying in regular institutions of higher education as a percentage of the total population in the cities as an indicator to measure the effect of human capital on economic efficiency.

Informatization level (Infor) is a "catalyst" that promotes economic efficiency. Improvements in informatization level will enable the rapid and effective transmission of information, thus saving time and information costs. The total volume of postal and telecommunication services was used to measure the effect of the informatization level on economic efficiency.

Industrial structure (Indus) is an important variable for distinguishing between regions' economic development levels. Due to the differences in technological progress and productivity rates between industries, the production factors shift from low-productivity sectors to high-productivity sectors, thus increasing the social productivity of the entire industry and generating "structural dividends" that promote economic efficiency [65]. The value added by tertiary industries as a percentage of the total output value was used to express the industrial structural characteristics of the BTH urban agglomeration.

Regarding land input (LS), land resources is self-evidently an important factor in promoting economic development by positively affecting economic growth [66]. In general, the area of urban built-up land is used to measure the city's level of land input. In accordance with this convention, this study used the area of urban built-up land to characterize the city's level of land input.

Economic openness (Open) has an impact on economic efficiency. When economic development increases rapidly, clear differences appear in the resource factors within the region compared with more developed regions. Therefore, expanding the degree of openness to the world can attract 


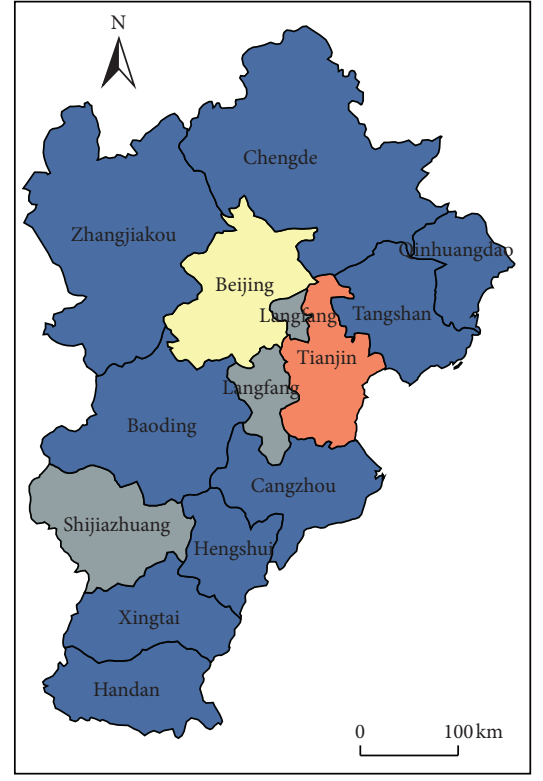

TFP 2009

$\square$ 0.767 0.817
$\square$ 0.818 0.921
$\square \quad$ 0.922 0.978

(a)

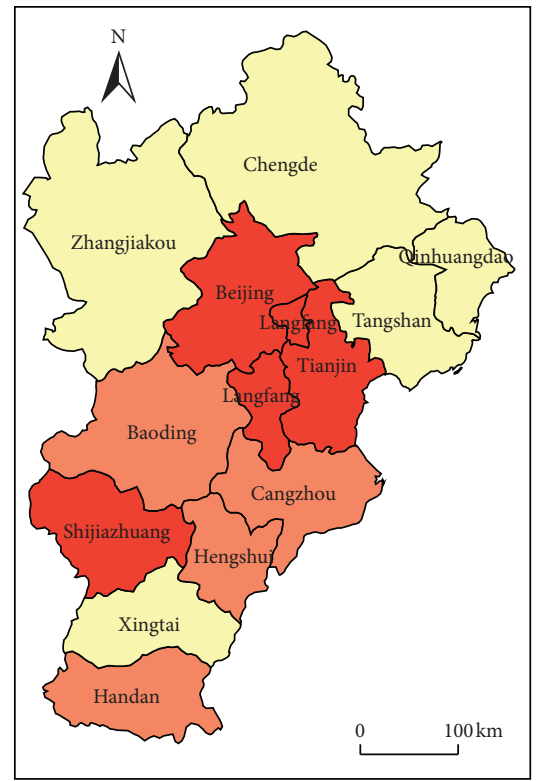

TFP 2015

$\square$ 0.922 0.978

$\square$ 0.979 1.007

$1.008 \sim 1.049$

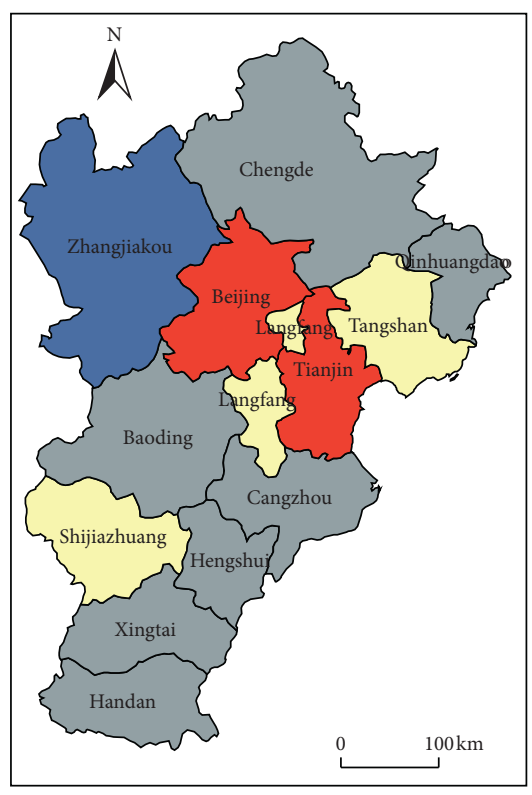

TFP 2011

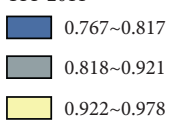

(b)

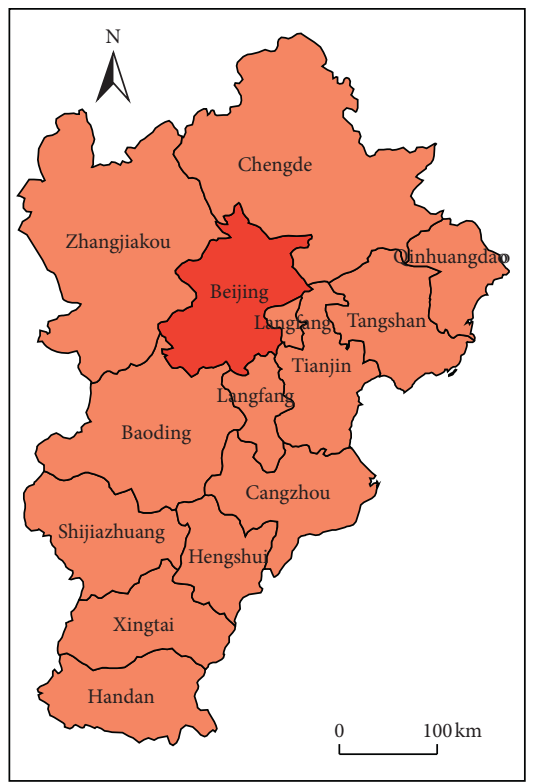

TFP 2017

$\square$ 0.979 1.007

$1.008 \sim 1.049$

(d)

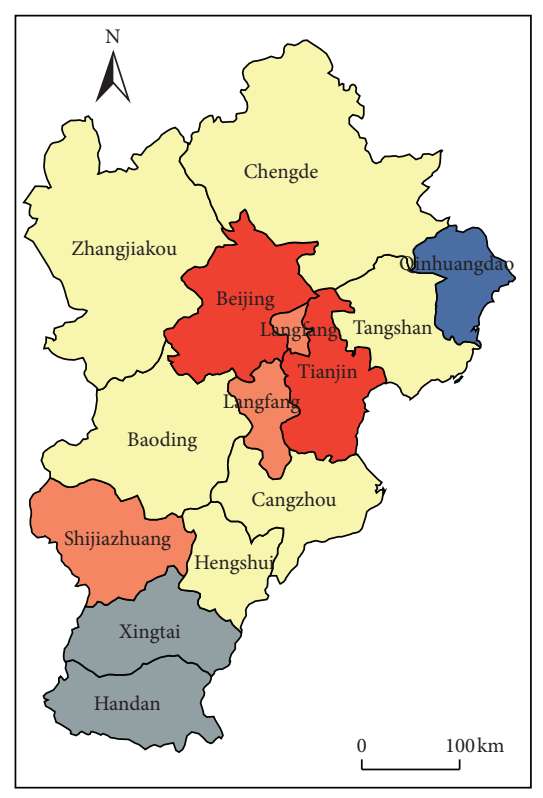

TFP 2013

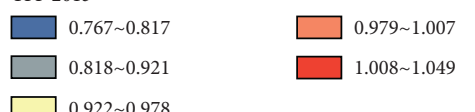

(c)

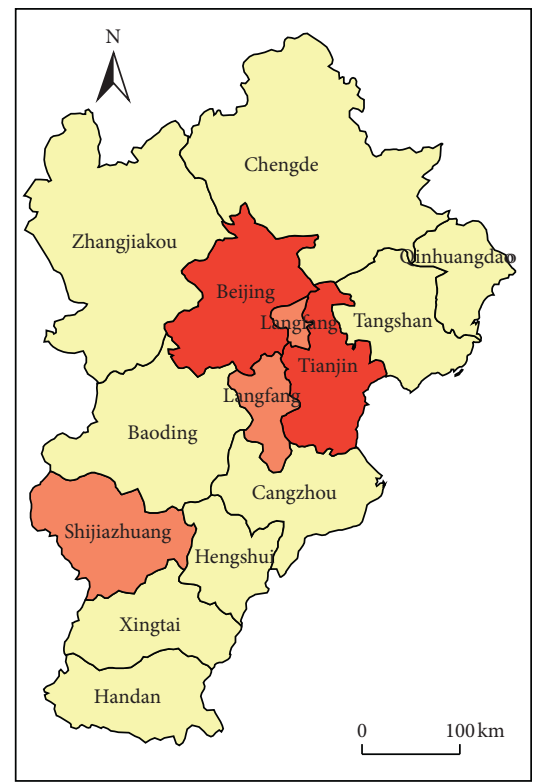

Mean TFP

$\square$ 0.818 0.921
$\square \quad 0.922 \sim 0.978$
$\square \quad 0.979 \sim 1.007$

(f)

Figure 2: TFP spatial pattern of Beijing-Tianjin-Hebei Metropolitan (2009-2017).

foreign investment, stimulate the vitality of private capital, and enable the introduction of advanced technology to enhance economic efficiency [67]. This study measured economic openness level using foreign direct investment as a percentage of the region's GDP in the corresponding year.
Governmental role (Gov) also affects the production and economic efficiency of the region. Governmental role is generally measured using the government consumption expenditure as a percentage of the overall consumption expenditure in GDP. This study adhered to this convention. 
Table 5: Malmquist index of Beijing-Tianjin-Hebei Metropolitan (2008-2017).

\begin{tabular}{lcccccccccc}
\hline Cities & 2008 & 2009 & 2010 & 2011 & 2012 & 2013 & 2014 & 2015 & 2016 & 2017 \\
\hline Beijing & 0.757 & 0.965 & 0.999 & 1.035 & 1.044 & 1.048 & 1.060 & 1.037 & 1.032 & 1.049 \\
Tianjin & 0.831 & 0.997 & 1.013 & 1.019 & 1.027 & 1.033 & 1.029 & 1.037 & 1.051 & 1.007 \\
Shijiazhuang & 0.673 & 0.854 & 0.926 & 0.971 & 0.981 & 0.985 & 0.993 & 1.02 & 1.028 & 1.000 \\
Tangshan & 0.643 & 0.817 & 0.915 & 0.951 & 0.966 & 0.971 & 0.953 & 0.975 & 0.999 & 1.000 \\
Qinhuangdao & 0.582 & 0.767 & 0.873 & 0.918 & 0.936 & 0.947 & 0.95 & 0.974 & 1.000 & 1.000 \\
Handan & 0.57 & 0.779 & 0.879 & 0.92 & 0.948 & 0.950 & 0.964 & 0.986 & 0.999 & 1.001 \\
Xingtai & 0.57 & 0.771 & 0.872 & 0.915 & 0.94 & 0.951 & 0.959 & 0.978 & 1.001 & 1.000 \\
Baoding & 0.575 & 0.778 & 0.886 & 0.918 & 0.948 & 0.963 & 0.969 & 0.988 & 1.002 & 1.000 \\
Zhangjiakou & 0.575 & 0.771 & 0.887 & 0.914 & 0.944 & 0.956 & 0.952 & 0.976 & 1.000 & 1.000 \\
Chengde & 0.584 & 0.778 & 0.866 & 0.919 & 0.948 & 0.968 & 0.975 & 0.974 & 1.000 & 1.000 \\
Cangzhou & 0.588 & 0.780 & 0.890 & 0.921 & 0.949 & 0.965 & 0.977 & 0.994 & 1.009 & 1.000 \\
Langfang & 0.718 & 0.875 & 0.938 & 0.964 & 0.971 & 0.985 & 0.985 & 1.031 & 1.039 & 1.000 \\
Hengshui & 0.562 & 0.768 & 0.883 & 0.919 & 0.947 & 0.966 & 0.979 & 0.993 & 1.008 & 1.000 \\
Mean & 0.633 & 0.823 & 0.910 & 0.945 & 0.965 & 0.976 & 0.98 & 0.997 & 1.013 & 1.004 \\
\hline
\end{tabular}

Table 6: Malmquist index and decomposition efficiency of Beijing-Tianjin-Hebei Metropolitan (2007-2017).

\begin{tabular}{|c|c|c|c|c|c|}
\hline Year & $\begin{array}{l}\text { Technical efficiency change } \\
\text { index }\end{array}$ & $\begin{array}{l}\text { Technology change } \\
\text { index }\end{array}$ & $\begin{array}{l}\text { Pure technical efficiency } \\
\text { change index }\end{array}$ & $\begin{array}{l}\text { Scale efficiency change } \\
\text { index }\end{array}$ & $\begin{array}{l}\text { Malmquist } \\
\text { index }\end{array}$ \\
\hline $2007-2008$ & 1.006 & 0.628 & 1.009 & 0.998 & 0.633 \\
\hline $2008-2009$ & 1.000 & 0.822 & 0.999 & 1.001 & 0.823 \\
\hline $2009-2010$ & 1.004 & 0.906 & 1.000 & 1.004 & 0.910 \\
\hline $2010-2011$ & 0.999 & 0.946 & 0.997 & 1.002 & 0.945 \\
\hline 2011-2012 & 0.996 & 0.969 & 1.005 & 0.991 & 0.965 \\
\hline $2012-2013$ & 0.996 & 0.980 & 1.003 & 0.993 & 0.976 \\
\hline 2013-2014 & 0.983 & 0.997 & 0.995 & 0.989 & 0.980 \\
\hline 2014-2015 & 0.980 & 1.017 & 0.995 & 0.985 & 0.997 \\
\hline $2015-2016$ & 0.983 & 1.030 & 0.996 & 0.987 & 1.013 \\
\hline $2016-2017$ & 1.026 & 0.979 & 1.002 & 1.026 & 1.004 \\
\hline Mean & 0.997 & 0.928 & 1.000 & 0.998 & 0.925 \\
\hline
\end{tabular}

Since government intervention will have a crowding-out effect on investment and reduce market efficiency [62], it is hypothesized that governmental role will have a negative effect on TFP.

Regarding science, technology, and education levels $(E d u)$, the improvement of science and education is conducive to the sustainable development of a regional economy [68]. At present, the transformation of economic growth from one driven by factor input to one driven by innovation lies at the core of transforming the new normal of economic growth. Such innovations are reflected mainly in technological and institutional innovations, as well as in the success of their transformation and whether they can truly become a major driving force behind economic development. The sum of local fiscal expenditures on science, technology, and education as a percentage of regional GDP was used to measure the support given to education, science, and technology by each city in the BTH urban agglomeration, in order to reflect its science, technology, and education level.

All indicator data were drawn from the same data sources as those described above and are thus not described here.

5.2. Model. The logical starting point of our study is the general form of the Cobb-Douglas production function (CD function). By taking TFP as the dependent variable and the spatial structure indicators as the independent variables, the model can be specified as follows:

$$
\ln T F P_{i t}=\xi+\gamma X_{i t}+\lambda Y_{i t}+\varepsilon_{i t} .
$$

In equation (7), $i$ denotes the various unit elements in the urban agglomeration; $t$ denotes time; $X_{i t}$ denotes the set of main independent variables in the model, which characterizes the internal spatial structure characteristics of the city; $Y_{i t}$ is the set of other control variables; $\varepsilon_{i t}$ is the random error term of the model; and $\xi, \gamma$ and $\lambda$ are undetermined coefficients.

\subsection{Econometric Tests}

5.3.1. Panel Unit Root Test. As panel data may have continuity and nonstationarity issues, it is necessary to test the stability of each variable prior to establishing the panel data model, as well as to perform cointegration tests to examine the long-term stable relationships between variables. Only when these tests produce satisfactory results can the regression model be established. The study used STATA 12.0 and employed LLC, IPS, $A D F$, and $P P$ as the main testing methods. As Table 7 shows, all tested variable time series passed the unit root test, and the null hypothesis was rejected. The results indicated that the selected variable time 
series were all stationary and of the same order of integration. Hence, cointegration testing was required.

5.3.2. Panel Cointegration Test. Due to the large number of variables in the regression model and given the attributes of the variables, the Kao residual-based cointegration test was performed. The results of the Kao residual-based cointegration test (see Table 8) indicate that the $A D F$ statistic was significant at the $1 \%$ level and the null hypothesis could be rejected. Therefore, the study's variables could be considered to have long-term stable relationships, while the model had cointegrated relationships. Hence, regression analysis could be performed on the spatial structure variables of the BTH urban agglomeration, the TFP of its economic efficiency, and other control variables.

5.3.3. Hausman Test. The Hausman test is mainly used to determine whether a fixed effects or random effects model should be chosen for the established model. The results indicated that a fixed effects (FEs) model was more suitable (see Table 9).

5.4. Econometric Results and Analysis. To avoid the problem of endogeneity between the variables, the statistical variables were subjected to first-order differential operation, followed by fixed effects regression model testing (see Table 10).

The results show that the primacy (Pri) of the urban agglomeration was positive, indicating that the monocentric spatial structure could enhance regional economic efficiency. The population is an important strategic resource, and its agglomeration within a certain range can optimize the allocation of factor resources, which facilitates regional economic development. Studies have shown that the largescale transfer and agglomeration of the labor force can promote regional industrial agglomeration. Population agglomeration can promote the optimization and upgrading of the industrial structure, while also enhancing regional economic competitiveness [69]. However, other scholars have proposed the opposite view, arguing that the excessive agglomeration of the population can produce a series of negative effects, thus hindering industrial development and economic growth [70]. Therefore, close attention must be paid to externalities, the crowding-out effect, and urban diseases brought about by excessive agglomeration. In addition, the primacy coefficient was positive, indicating that the higher the urban primary, the greater the economic radiation capacity of the urban agglomeration. Over the past 40 years of reform and opening up, the BTH urban agglomeration has attained significant economic development achievements, but the regional development within the urban agglomeration has been unequal. This is manifested by the insufficient urban functions fulfilled by the capital city and its inadequacies in driving the economy of the urban agglomeration. In the new era of high-quality development, urban primacy is accompanied by unique agglomeration advantages, complete functional advantages, and the capacity for regional interconnection and integration.
Therefore, optimizing the spatial structure of the BTH urban agglomeration will require divesting noncapital functions to achieve the spatial reallocation of resources in the BTH megaregion; optimizing the BTH urban system by constructing the Xiong'an New District at its core to implement a polycentric strategy and promote the internal spatial optimization of megacities; promoting differential development in Hebei Province through the integration of large cities and the specialization of small and medium-sized cities; and supporting the barrier-free and efficient flow of various factors in the BTH megaregion with interregional high-speed transportation systems [71].

The dispersion degree passed the test at the 5\% significance level, indicating that the spatial structure of agglomeration has a positive facilitative effect on economic development. Thus, positive externalities are produced in the economies of scale brought about by agglomeration, including cost advantages, knowledge spillover, technological innovation, and other benefits, which promote improvements in the economic efficiency of urban agglomerations. This conclusion is largely consistent with the findings of other scholars that the industrial and population agglomeration of smaller cities can avoid the negative externalities of larger cities, while also obtaining external economies of scale [32]. However, Henderson argues that the environmental, transportation, and other problems that arise amid population agglomeration cause external diseconomies [72], which hinder the improvement of economic efficiency. Other studies have proposed that there is an optimal agglomeration level in urban agglomerations and that, if the agglomeration level is lower than this optimal value, the urban agglomeration will not be able to achieve the optimal level of resource allocation, whereas a higher-than-optimal level will lead to excessive agglomeration, causing diseconomies of scale and loss of efficiency [73].

Studies have revealed a positive relationship between city size and economic efficiency. City size is an externality of economic agglomeration. Under the mechanisms of agglomeration, production factors foster the ever-strengthening force of urban agglomeration, and the urban structure will tend to polarize towards a monocentric spatial structure [74]. However, when cities become too large, the advantages of the monocentric spatial structure weaken, leading to urban diseases such as crowded populations, resource scarcity, and environmental pollution; reverse centrifugal forces can even appear during agglomeration [75]. The negative external transaction costs generated by population and industrial agglomeration will also gradually exceed the benefits generated by the economies of scale in urban agglomerations, ultimately leading to the spatial structure's transformation from monocentricism to polycentricism. At this point, a polycentric spatial structure is more conducive to improving regional economic efficiency $[33,34,76]$. Therefore, with respect to megaregions, a polycentric spatial structure is a highly efficient mode of agglomeration, and a polycentric spatial layout should be adopted. For cities within the megaregional limits, a monocentric spatial distribution can provide higher labor productivity $[15,77]$. 
TABLE 7: Test results of unit root.

\begin{tabular}{|c|c|c|c|c|}
\hline \multirow{2}{*}{ Model } & \multicolumn{4}{|c|}{ Test statistics } \\
\hline & $L L C$ & IPS & $A D F$ & $P P$ \\
\hline $\ln T F P$ & $-10.291^{* * *}(0.000)$ & $-4.572^{* * *}(0.000)$ & $48.201^{* * *}(0.005)$ & $354.161^{* * *}(0.000)$ \\
\hline Pri & $-5.304^{* * *}(0.000)$ & $-1.949^{* *}(0.026)$ & $44.094^{* *}(0.015)$ & $92.830^{* * *}(0.000)$ \\
\hline Dis & $-4.750^{* * *}(0.000)$ & $-0.047(0.481)$ & $37.059^{*}(0.074)$ & $20.258(0.779)$ \\
\hline$\triangle D i s$ & $-9.709^{* * *}(0.000)$ & $-5.122^{* * *}(0.000)$ & $59.417^{* * *}(0.003)$ & $53.907^{* * *}(0.000)$ \\
\hline Gini & $-3.185^{* * *}(0.001)$ & $-3.063^{* * *}(0.000)$ & $40.665^{* *}(0.034)$ & $77.929^{* * *}(0.000)$ \\
\hline $\ln p o p$ & $-4.670^{* * *}(0.000)$ & $-0.512(0.304)$ & $29.846^{* * *}(0.274)$ & $19.271^{* * *}(0.825)$ \\
\hline$\triangle \ln p o p$ & $-10.113^{* * *}(0.000)$ & $-4.088^{* * *}(0.000)$ & $63.021^{* * *}(0.000)$ & $48.143^{* *}(0.016)$ \\
\hline $\ln p o p * D i s$ & $-5.850^{* * *}(0.000)$ & $-0.805(0.211)$ & $37.133^{* *}(0.073)$ & $27.211(0.398)$ \\
\hline$\triangle \ln p o p * D i s$ & $-13.297^{* * *}(0.000)$ & $-3.143^{* * *}(0.000)$ & $61.843^{* * *}(0.000)$ & $77.176^{* * *}(0.000)$ \\
\hline Hum & $-2.772^{* * *}(0.000)$ & $-2.487^{* * *}(0.000)$ & $57.134^{* * *}(0.000)$ & $50.650^{* * *}(0.003)$ \\
\hline Infor & $-7.961^{* * *}(0.000)$ & $-1.986^{* * *}(0.024)$ & $48.371^{* * *}(0.005)$ & $55.560^{* * *}(0.001)$ \\
\hline Indus & $-6.196^{* * *}(0.000)$ & $-4.673^{* * *}(0.000)$ & $75.325^{* * *}(0.000)$ & $93.757^{* * *}(0.000)$ \\
\hline$L S$ & $-3.442^{* * *}(0.003)$ & $-3.970^{* * *}(0.000)$ & $58.270^{* * *}(0.000)$ & $84.086^{* * *}(0.000)$ \\
\hline Open & $-2.945^{* * *}(0.002)$ & $-2.839^{* * *}(0.002)$ & $50.927^{* * *}(0.006)$ & $90.288^{* * *}(0.000)$ \\
\hline Gov & $-3.712^{* * *}(0.000)$ & $-2.374^{* * *}(0.009)$ & $62.439^{* * *}(0.000)$ & $89.102^{* * *}(0.000)$ \\
\hline$E d u$ & $-38.665^{* * *}(0.000)$ & $-22.922^{* * *}(0.000)$ & $47.454^{* *}(0.006)$ & $575.675^{* * *}(0.000)$ \\
\hline
\end{tabular}

Note: ${ }^{*},{ }^{* *},{ }^{* *}$, and ${ }^{* *}$ rejection of the original hypothesis at the significance level of $10 \%, 5 \%$, and $1 \%$, respectively; the value in brackets is the test $p$ value of the corresponding variable; $\Delta$ indicates the first-order difference test on the original test result for the variable.

TABLE 8: The results of Kao test.

\begin{tabular}{lcc}
\hline Variable & T-statistic & Prob. \\
\hline$A D F$ & -3.016 & $0.000^{* * *}$ \\
Residual & 0.009 & \\
$H A C$ variance & 0.005 & \\
\hline
\end{tabular}

Note: ${ }^{* * *}$ rejection of the original hypothesis at a significant level of $1 \%$.

TABLE 9: The results of the Hausman test.

\begin{tabular}{lccc}
\hline Test Summary & Chi-sq. statistic & Chi-sq. df. & Prob. \\
\hline Cross section random & 38.156 & 16 & $0.002^{* * *}$ \\
\hline
\end{tabular}

Note: ${ }^{* * *}$ rejection of the original hypothesis at a significant level of $1 \%$.

The study's results show that the coefficient of the interaction term Inpop ${ }^{*}$ Dis was negative, indicating that the impact caused by the spatial structure characteristics of the urban agglomeration on regional economic efficiency is determined by its size. For smaller urban agglomerations, a monocentric spatial structure is more conducive to improving economic efficiency. For larger urban agglomerations, however, the advantages of a monocentric development strategy will be diminished, while also unavoidably giving rise to fierce competition among core cities for resource factors and the accompanying agglomeration diseconomies, such as traffic congestion, reduced ecological carrying capacity, increased land prices, and hydropower costs, which will restrict their economic development. In addition, due to the expansion in size and presence of spatial distances, new agglomeration centers will gradually form within the urban agglomerations [78] in order to take on part of the urban roles and functions. Therefore, when the population of an urban agglomeration reaches a certain size, a polycentric spatial layout is more beneficial to regional economic development [79]. Lee (2006) has shown that the urban spatial structure changes with the city's development stage and size and that there is no optimal urban spatial layout. However, other studies have shown that the polycentric spatial structure has varying effects on economic performance due to the impacts of heterogeneous factors such as city size and development stage [80]. Therefore, future plans for spatial development should scientifically and rationally allocate the distribution of factor resources according to the development stage and size of the urban agglomeration in order to form a rational and orderly mode of spatial structure that supports coordinated development, thereby improving the quality of economic development in the urban agglomeration [33, 76].

The study also found that urban population size had a significantly positive effect on economic efficiency, indicating that population agglomeration within the BTH urban agglomeration can help to exert the advantages brought about by the economies of scale in urban agglomerations. A number of studies have also shown that population agglomeration can provide external economies of scale $[32,69,81]$, but the negative effects caused by excessive agglomeration should be prevented in the development of urban agglomerations. The population size of the BTH urban agglomeration is in a weakly agglomerated state, with large gaps between the population sizes of cities within the urban agglomeration. By contrast, its economic size is in a strongly agglomerated state, with uncoordinated regional economic development [82]. If high-quality factor resources are further concentrated in Beijing and Tianjin, these cities will face even more serious population and economic pressures, as well as exacerbated spatial polarization [61]. Therefore, the effective control and rational spatial layout of population size in the BTH urban agglomeration are important for its coordinated development and the full use of its advantages in economies of scale. The top-level design of the urban agglomeration should be enhanced, combined with the functional layout of the BTH megaregion, in order to formulate differential policies to guide the rational flow of 
TABLE 10: Regression results of impact of spatial structure on economic efficiency.

\begin{tabular}{lcccc}
\hline Model & Model 1 & Model 2 & Model 3 & Model 4 \\
\hline Pri & & & $0.182^{*}(1.668)$ & $0.211^{* *}(1.990)$ \\
Dis & $-0.364(-0.688)$ & $-1.055^{* *}(-1.909)$ & $-0.929(-1.411)$ & $-1.737^{* *}(-2.704)$ \\
Gini & & & $0.176(0.589)$ & $0.141(0.499)$ \\
lnpop & $0.3067(1.383)$ & $0.502^{* * *}(3.977)$ & $0.680^{* * *}(3.050)$ & $0.845^{* *}(2.129)$ \\
lnpop ${ }^{*}$ Dis & & $0.316^{* *}(1.994)$ & $0.026^{* *}(2.004)$ & $0.402^{* *}(2.440)$ \\
Hum & $0.035^{* * *}(2.774)$ & $0.030^{* *}(2.302)$ & $0.057(0.983)$ & $0.022^{* *}(1.739)$ \\
Infor & $0.034(0.691)$ & $0.049(0.832)$ & $0.036(0.899)$ & $0.069^{*}(1.416)$ \\
Indus & $0.029(0.579)$ & $0.031(0.753)$ & $-0.205^{* *}(-2.005)$ & $0.038(1.010)$ \\
LS & $-0.175^{*}(-1.737)$ & $-0.198^{*}(-1.890)$ & $-0.029(-0.447)$ & $-0.255^{* *}(-2.211)$ \\
Open & $-0.033(-0.601)$ & $-0.032(-0.523)$ & $-0.038(-0.591)$ & $-0.027(-0.399)$ \\
Gov & $-0.029(-0.466)$ & $-0.031(-0.538)$ & $0.337^{* *}(2.225)$ & $-0.049(0.731)$ \\
Edu & $0.262^{* *}(1.910)$ & $0.300^{* *}(2.140)$ & 0.653 & $0.359^{* *}(2.402)$ \\
Adjusted $R^{2}$ & 0.649 & 0.641 & $15.383^{* *}$ & 0.667 \\
F-statistic & $16.076^{* *}$ & $15.712^{* *}$ & 1.96 & $14.856^{* *}$ \\
DW & 1.97 & 1.93 & 1.92 \\
\hline
\end{tabular}

Note: the values in brackets are statistics $t ;{ }^{*},{ }^{* *},{ }^{* *}$, and ${ }^{* *}$ significant at the significance level of $10 \%, 5 \%$, and $1 \%$, respectively.

the population and to form a polycentric spatial pattern for the population in the BTH megaregion [83].

Our findings indicate that human capital, informatization level, industrial structure, and science and technology levels all had positive effects on economic efficiency; whereas governmental role, economic openness, and land input had negative effects. Human capital is an important indicator used in classical economics and new growth theory to explain economic growth. This study also lends support to the conclusion that human capital has a positive impact on economic growth [84]. However, other scholars have pointed out that there is a development stage and regional heterogeneous cointegrated relationship between human capital and economic growth. When the regional economy is underdeveloped, the positive facilitative effect between human capital and economic growth is not significant [85]. Therefore, urban agglomerations need to continuously optimize the structure of human resources, improve the level of human capital in a diversified manner, and effectively combine the power of supply-side reform with the upgrading of human resources, thereby achieving integrated development talents in the BTH megaregion through measures such as innovation and entrepreneurship, education system reform, and skill training. Informatization was found to have a positive impact on economic efficiency, indicating that informatization can reduce the operational costs of enterprises, accelerate the interactions and communications among enterprises and regions, help overcome the problem of information asymmetry in the market, and enable economic agents to more effectively utilize new technologies and methods for production, thereby enhancing the operational efficiency of the economy in the urban agglomeration. This study found that industrial structure had a positive effect on the TFP of the BTH urban agglomeration, largely because the BTH urban agglomeration is still in a stage of accelerated industrialization; hence, the technological innovation and upgrading of industries could significantly improve labor productivity [86]. Therefore, achieving high-quality economic growth will require vigorously developing modern service industries; accelerating industrial transformation [87], optimization, and upgrading, so as to obtain the scale economy, scope economic benefit and technology spillover benefit brought by industrial agglomeration [88]; formulating corresponding industrial development policies that adhere to the patterns of industrial evolution [89]; and providing investments of government capital in the form of state-owned investment companies in order to guide the transformation of investment and industrial structures [90].

This study found that governmental role reduces the efficiency of economic development. This may be due to the fact that government intervention crowds out the private sector and reduces the input and output of investments in the market, thereby causing low growth and instability of economic efficiency. The government should thus continue a policy of "streamlining and decentralization"; clarify the "three lists" of prohibitions, powers, and responsibilities; and revitalize the market economy. Our findings also showed that land input had a negative effect on economic efficiency, indicating that increasing the built-up land in the urban areas of the BTH megaregion did not promote improvements in economic efficiency. In the early stages of urban development, measures designed to increase land use can have a significant facilitative effect on the urban economy. However, as the urban economic structure continues to improve, excess land input will instead lead to diseconomies of scale in land use efficiency, causing land input to hinder improvements in regional economic efficiency. Thus, improving land input-output efficiency and promoting an appropriate level of regional economic growth will require us to reverse the diseconomies of scale caused by land use efficiency.

Regarding the relationship between economic openness and growth, greater openness will enhance the capacity to attract external investments, advanced technology, and management experience, which all play a crucial role in improving regional economic efficiency. Most scholars also agree that openness to the outside world has a positive effect on local economic performance [91]. Our findings indicate that economic openness did not have a significant effect on 
regional economic efficiency. Theoretically, increasing economic openness could rapidly increase the total volume and efficiency of economic development for areas in the early stages of regional construction or that are lagging behind $[67,92]$. However, given the gradual completion of regional construction, regional development is no longer a matter of increasing "volume" but of improving the "quality" of economic efficiency. In addition, the presence of foreign companies with high pollution levels, high energy consumption, and low efficiency poses a threat to the regional ecological environment and hinders the improvement of regional green TFP, thus causing negative effects on regional economic development [93]. Therefore, the effects of foreign investment on improving the economic efficiency of urban agglomerations will weaken over time.

\section{Conclusion and Discussion}

6.1. Conclusion. In this study, primacy, dispersion, and the Gini coefficient of city size and urban population size were used to characterize the spatial structure evolution of the BTH urban agglomeration, while TFP was used to describe the evolutionary patterns of economic efficiency in the agglomeration. These were then combined with control variables for model construction in order to examine the effects of spatial structure on economic efficiency in the BTH urban agglomeration. Our conclusions are as follows:

(1) Development within the BTH urban agglomeration is unequal, with significant differences in spatial structure. The calculation results of various indicators used to characterize spatial structure reveal varying change trends among the indicator variables. The mean values of primacy and dispersion have increased gradually, whereas the standard deviation of primacy has decreased, and the Gini coefficient of city size has shown a fluctuating trend. In terms of urban population size, the populations of most cities were still in a dispersed state. Although urban populations have tended to agglomerate around multiple subcenter units in the cities, the trend towards population agglomeration around city centers was not significant.

(2) During the study period, the TFP of the BTH urban agglomeration was not high, showing a fluctuating downward trend overall. The TFP of the urban agglomeration showed differential regional patterns across different years. The decline in the growth rate of TFP in the BTH urban agglomeration is mainly due to the decrease in technological progress, technological efficiency, and scale efficiency. Resource input remains the major driving force behind the development of the BTH megaregion.

(3) Regarding the effects of the urban agglomeration spatial structure on economic efficiency, the study found that primacy, the urban Gini coefficient, and urban population size had positive effects on economic efficiency, whereas the effect of dispersion was not statistically significant. This shows that the spatial structure of agglomeration plays a positive role in promoting economic development. The population agglomeration within the BTH urban agglomeration is conducive to yielding the full extent of the advantages of the scale of the agglomeration economy. The impact of spatial structure characteristics on economic performance depends on the size of urban agglomeration; in smaller urban agglomerations, the spatial structure of a single center is more conducive to the improvement of economic efficiency of the agglomeration. However, in larger urban agglomerations, the advantages of a single center development strategy will be reduced. As a result, by facing the strong competition of core cities for resource elements and the accompanying traffic congestion, the reduction of ecological carrying capacity, the increase in land price and water and electricity costs, and other nonagglomeration economic challenges, the economic development of urban agglomerations is restricted. In terms of the control variables, human capital, informatization level, industrial structure, and science and technology levels had significantly positive effects on economic efficiency, whereas governmental role, economic openness, and land input had negative effects on economic efficiency.

6.2. Discussion. China's economic growth has entered a stage of high-efficiency development, implying the formation of the three-in-one industrial mode of capital, talent, and innovation. Innovation has now become the core driver of improvement in regional economic efficiency, while economic development is preparing to move towards a stage of high efficiency. Therefore, to achieve the integrated development of the BTH megaregion, narrow the economic gap, and establish a world-class urban agglomeration with Beijing as the core, it is necessary to optimize the spatial structure of the urban agglomeration and transform the mode of economic development.

(1) Constructing a scientific and rational regional spatial system and strengthening internal cooperation within the urban agglomeration: the spatial structure of an urban agglomeration is an important starting point for achieving its economic growth. The rapid development of the Chinese economy and the acceleration of the urbanization process have made agglomeration diseconomies increasingly prominent. High housing prices and costs of living have caused the population to migrate from megacities and large cities to medium-sized cities, which has in turn widened the gaps within the city and restricted regional economic development. Although various areas have made corresponding spatial adjustments and strategic deployments, the strong path dependence in the evolution of the spatial structure in urban agglomerations has hindered transformation. By analyzing how the spatial structure of the BTH 
urban agglomeration impacts economic efficiency, this study confirmed that spatial structure is an important starting point for economic development and that building a scientific and rational regional spatial system is an effective means by which to achieve the sustainable and healthy development of the BTH urban agglomeration economy. Comprehensive, rational, and scientific top-level design and overall planning are the basis for scientifically guiding the efficient and orderly progress of urban agglomerations. Beijing should divest itself of noncapital functions at an accelerated pace. Tianjin and Hebei Province should vigorously promote the construction of new urbanization and urban-rural integrated demonstration zones, expand the size of central cities, actively establish satellite cities, and accelerate their integration into the world-class BTH urban agglomeration.

(2) Orderly divesting of noncapital functions and reshaping the industrial patterns of the BTH urban agglomeration: by the end of 2018, the urbanization rate of the BTH megaregion had reached $65.8 \%$, which is much higher than China's overall urbanization rate (59.58\%), indicating that the BTH urban agglomeration has entered the era of the urban society. This also implies that urban agglomerations will inevitably experience greater labor transfer from primary to tertiary industries. Therefore, regulations of population sizes in urban agglomerations should be amended rather than restricted. Development in the various links of the BTH industrial chain is currently unequal. This is manifested in the difficulty of achieving the upstream and downstream integration of established industrial chains and high-tech industries such as intelligent and high-end manufacturing, as well as the low upstream and downstream matching rate. In addition, the lack of support for the manufacturing system of the urban agglomeration constrains the successful transformation of scientific and technological achievements and weakens the agglomeration's capacity to promote regional economic efficiency. Studies have shown that population and industrial agglomeration can facilitate the improvement of regional economic efficiency. Therefore, the BTH urban agglomeration should expand spaces for regional population growth and construct a rational industrial chain layout. Beijing should guide the orderly dismantling of industries, focus on the construction of larger new suburban cities in the periphery of the central urban areas, and build manufacturing clusters at key nodes. Tianjin should play a leading role in taking on the noncapital functions of Beijing, thereby enhancing its urban functions, optimizing the regional development environment, encouraging innovative and leading enterprises to set up corporate development strategic institutions in Beijing, and building production bases in Hebei Province. Hebei Province should also guide the development of the population and economy towards the Binhai New Area and use the free-trade zone to enhance its transfer capacity. It should also rely on the Port of Tianjin, Tianjin Airport, Binhai New Area, Daxing Airport, and other areas to improve the support facilities and services of its transfer platform; assume Beijing's divested noncapital functions and transformation of scientific and technological achievements; and support the intensive cooperation of Beijing and Tianjin with the free-trade zone to achieve innovative development.

(3) Establishing core cities in the BTH urban agglomeration and enhancing the development level of regional central cities: with respect to the hierarchical system of city size, the BTH urban agglomeration has two megacities (Beijing and Tianjin) but lacks supercities. The break in the hierarchy of city size within the urban agglomeration will hinder its internal transmission of industries and innovation, thus affecting the construction of cross-regional industrial chain systems. Studies have shown that increasing the population and economic size of regional central cities in urban agglomerations can help promote the development of regional central cities. BTH urban agglomeration can improve its innovation capacity by creating urban centers with their respective central cities at the core and can strengthen the impact of central cities on the BTH urban agglomeration by providing professional services. Regarding Beijing, the noncapital functions of "overdense" areas should be divested, a "polycentric, networked" spatial layout should be established, and capital functions should be reconfigured in order to achieve a rational layout of Beijing's urban economic functions. Based on their comparative advantages, Tianjin and Hebei Province should be more proactive in deepening their connections with noncapital functions, as well as in perfecting and utilizing the functions of industrial agglomeration, location attraction, and service robustness.

6.3. Research Prospect. There are also some limitations to this study. For example, this paper is mainly based on the macroresearch of Beijing, Tianjin, and Hebei cities, while we are unable to explore smaller scales, such as the impact of county-level spatial structure on economic efficiency, or reflect the impact of spatial structure on individuals and enterprises. In addition, due to data availability, the data collection of the BTH urban agglomeration is only based on the urban and county areas and does not further investigate the microscale of towns and roads. In the future, the research on the comprehensive effect of multiscale spatial structure of urban agglomerations based on big data mining will be more advantageous to solve the contradictions in the process of urbanization, to further understand the law reform of urban agglomerations, and to promote the construction and development of urban agglomerations through economic efficiency, all-inclusiveness, and livability. 


\section{Data Availability}

The primary data used to support the findings of this study have been explained clearly in Section 3.3.

\section{Conflicts of Interest}

There are no conflicts of interest among authors.

\section{Acknowledgments}

This study acknowledges the support of the NSFC (National Natural Science Foundation of China) under project numbers 41771131 and 41671120 and Premium Funding Project for Academic Human Resources Development in Beijing Union University under project number BPHR2020AS02.

\section{References}

[1] J. Friedmann and A. Sorensen, "City unbound: emerging mega conurbations in Asia," International Planning Studies, vol. 24, no. 1, pp. 1-12, 2019.

[2] S. Wang, Y. Wang, and D. Wang, "Spatial structure of central places in jilin central urban agglomeration, jilin Province, China," Chinese Geographical Science, vol. 24, no. 3, pp. 375-383, 2014.

[3] D. S. Yan and J. Yang, "Change in spatial distribution of population and economy and influencing factors in the Yangtze River Delta," Progress in Geography, vol. 36, no. 7, pp. 820-831, 2017, in Chinese.

[4] F. M. Peng, "Economic spatial connection and spatial structure of guangdong-Hong Kong-Macao greater bay and the surrounding area cities-an empirical analysis based on improved gravity model and social network analysis," Economic Geography, vol. 27, no. 12, pp. 1-12, 2007, in Chinese.

[5] R. Camagni, R. Capello, and A. Caragliu, "Static vs. dynamic agglomeration economies. Spatial context and structural evolution behind urban growth," Papers in Regional Science, vol. 95, no. 1, pp. 133-158, 2015.

[6] H. Marco and L. Micheal, "Spatial analysis of the urban-torural migration determinants in the Viennese metropolitan area. A transition from suburbia to postsuburbia?" Applied Spatial Analysis and Policy, vol. 2, pp. 237-260, 2009.

[7] M. Dong, B. Zou, Q. Pu, N. Wan, L. Yang, and Y. Luo, "Spatial pattern evolution and casual analysis of county level economy in Changsha-Zhuzhou-Xiangtan urban agglomeration, China," Chinese Geographical Science, vol. 24, no. 5, pp. 620-630, 2014.

[8] T. L. Zhang and B. D. Sun, "The interaction between urban spatial structure and economic development," Scientia Geographica Sinica, vol. 37, no. 4, pp. 512-518, 2017, in Chinese.

[9] G. P. Li, Z. Wu, and T. S. Sun, "A review and prospect of research on regional spatial structure in China," Economic Geography, vol. 32, no. 4, pp. 6-11, 2012, in Chinese.

[10] Y. Zhao and H. K. Wei, "The government intervention, the division of labor of the function of the space of the city group, and the difference in district: on the effectiveness of regional policy in China," Management World, vol. 8, pp. 14-29, 2015, in Chinese.

[11] Z. C. Wei, K. Y. Wang, and T. T. Chen, "Transformation of economic and technological development zones in the context of new urbanization: a case study of the Guangzhou Private
Science and Technology Park," Progress in Geography, vol. 34, no. 9, pp. 1195-1208, 2015, in Chinese.

[12] Y. Zhang, G. B. Ye, and S. M. Yao, "The interactive study on new town construction of development zone and urban expansion: taking shanghai, hangzhou and nanjing as an example," Economic Geography, vol. 35, no. 2, pp. 84-91, 2015, in Chinese.

[13] C. X. Li, X. Gao, B. J. He, J. Y. Wu, and K. N. Wu, "Coupling coordination relationships between urban-industrial land use efficiency and accessibility of highway networks: evidence from beijing-tianjin-hebei urban agglomeration, China," Sustainability, vol. 11, no. 5, pp. 1-23, 2019.

[14] J. Yang, A. Guo, Y. Li, Y. Zhang, and X. Li, "Simulation of landscape spatial layout evolution in rural-urban fringe areas: a case study of Ganjingzi District," GIScience \& Remote Sensing, vol. 56, no. 3, pp. 388-405, 2019.

[15] B. D. Sun and W. Li, "City size distribution and economic performance: evidence from city-regions in China," Scientia Geographica Sinica, vol. 36, no. 3, pp. 328-334, 2016, in Chinese.

[16] C. L. Fang, "Progress and the future direction of research into urban agglomeration in China," Acta Geographica Sinica, vol. 69, no. 8, pp. 1130-1144, 2014, in Chinese.

[17] C. Fang, Q. Gao, X. Zhang, and W. Cheng, "Spatiotemporal characteristics of the expansion of an urban agglomeration and its effect on the eco-environment: case study on the northern slope of the Tianshan Mountains," Science China Earth Sciences, vol. 62, no. 9, pp. 1461-1472, 2019.

[18] P. Zeng, T. Y. Huang, and F. F. Que, "Comparative study on spatial structure characteristics of Chinese ten top urban agglomeration," Economic Geography, vol. 31, no. 4, pp. 603-608, 2011, in Chinese.

[19] F. Q. Niu, X. Y. Yang, and F. Wang, "Urban agglomeration formation and its spatiotemporal expansion process in China: from the perspective of industrial evolution," Chinese Geographical Sciences, vol. 30, no. 3, pp. 1-12, 2020.

[20] Y. H. He, G. H. Zhou, C. L. Tang, X. L. Tan, Z. Chen, and S. G. Fan, "Theory on the spatial organization of urban-rural integration in urban agglomeration areas," Geographical Research, vol. 36, no. 2, pp. 241-252, 2017, in Chinese.

[21] L. Wang, Y. Deng, and W. Y. Niu, "The definition and identification of urban agglomerations," Acta Geographica Sinica, vol. 68, no. 8, pp. 1059-1070, 2013, in Chinese.

[22] H. L. Miao and H. Zhou, "A comparative analysis on economic linkage and hierarchical structure of the top three urban agglomerations in China-using a synthesized gravity model," Economic Geography, vol. 37, no. 6, pp. 52-59, 2017, in Chinese.

[23] J. C. Huang and S. Q. Chen, “Classification of China's urban agglomerations," Progress in Geography, vol. 34, no. 3, pp. 290-301, 2015, in Chinese.

[24] B. Gao, Q. Huang, C. He, and Y. Dou, "Similarities and differences of city-size distributions in three main urban agglomerations of China from 1992 to 2015: a comparative study based on nighttime light data," Journal of Geographical Sciences, vol. 27, no. 5, pp. 533-545, 2017.

[25] L. W. Wang and C. C. Feng, "Spatial expansion pattern and its driving dynamics of Beijing-Tianjin-Hebei metropolitan region: based on nighttime light data," Acta Geographica Sinica, vol. 71, no. 12, pp. 2155-2169, 2016, in Chinese.

[26] J. Ding and K. Y. Wang, "Spatial pattern and morphological characteristics of industrial production space and influential factors in the Pearl River Delta urban agglomeration," 
Progress in Geography, vol. 35, no. 5, pp. 610-621, 2016, in Chinese.

[27] L. Zhang and Y. Lu, "Regional accessibility of land traffic network in the Yangtze River Delta," Journal of Geographical Sciences, vol. 17, no. 3, pp. 351-364, 2007.

[28] H. Chen and G. Li, "Empirical study on effect of industrial structure change on regional economic growth of BeijingTianjin-Hebei metropolitan region," Chinese Geographical Science, vol. 21, no. 6, pp. 708-714, 2011.

[29] M. Brezzi and P. Venerri, "Assessing polycentric urban systems in the OECD: country, regional and metropolitan perspectives," European Planning Studies, vol. 23, pp. 10171037, 2015.

[30] R. Capello, "The city network paradigm: measuring urban network externalities," Urban Studies, vol. 37, no. 11, pp. 1925-1945, 2000.

[31] J. B. Parr, "Agglomeration economies: ambiguities and confusions," Environment and Planning A: Economy and Space, vol. 34, no. 4, pp. 717-731, 2002.

[32] W. Alonso, "Urban zero population growth," Daedalus, vol. 109, no. 4, pp. 191-206, 1973.

[33] N. A. Phelps, "Clusters, dispersion and the spaces in between: for an economic geography of the Banal," Urban Studies, vol. 41, no. 5-6, pp. 971-989, 2004.

[34] B. D. Sun, R. Guo, and Y. Chen, "Spatial structure and economic performance of Chinese city clusters policy implications for spatial planning of city clusters," City Planning Review, vol. 43, no. 9, pp. 37-42, 2019, in Chinese.

[35] X. Y. Liu, S. L. Li, and M. Qin, "Urban spatial structure and regional economic efficiency-on the mode choice of China's urbanization development," Management World, vol. 1, pp. 51-64, 2017, in Chinese.

[36] E. J. Meijers and M. J. Burger, "Spatial structure and productivity in US metropolitan areas," Environment and Planning A: Economy and Space, vol. 42, no. 6, pp. 1383-1402, 2010.

[37] M. Abramovitz, "Resource and output trends in the United States since 1870," The American Economic Review, vol. 46, no. 2, pp. 5-23, 1956.

[38] Q. Q. Liu, W. Z. Zhang, S. J. Wang, B. Li, and D. S. Zhang, "Evaluating the efficiency of urban municipal public facilities and its influence on economic development in China," Geographical Research, vol. 36, no. 9, pp. 1627-1640, 2017, in Chinese.

[39] N. Najkar, M. R. Kohansal, and M. Ghorbani, "Impact of industrial agglomeration on productivity: evidence from Iran's food industry," Chinese Geographical Science, vol. 30, no. 2, pp. 309-323, 2020.

[40] J. G. Liu, "The influencing factors and its mechanism of regional economic efficiency and total factors productivity," Economic Geography, vol. 34, no. 7, pp. 7-11, 2014, in Chinese.

[41] R. Z. Li, Y. B. Liu, and D. J. Xie, "Evolution of economic efficiency and its influencing factors in the industrial structure changes in China," Acta Geographica Sinica, vol. 72, no. 12, pp. 2179-2198, 2017, in Chinese.

[42] K. Zhao, T. Q. Xu, and A. L. Zhang, "Urban land expansion, economies of scale and quality of economic growth," Journal of Natural Resources, vol. 31, no. 3, pp. 390-401, 2016, in Chinese.

[43] J. C. Huang, H. X. Lin, and M. Chen, "The dynamics and empirical analysis of input and output efficiency of urban agglomerations in China, 2000-2013: based on the DEA model and Malmquist index method," Progress in Geography, vol. 36, no. 6, pp. 685-696, 2017, in Chinese.
[44] A. Bergeaud, G. Cette, and R. Lecat, "The role of production factor quality and technology diffusion in twentieth-century productivity growth," Cliometrica, vol. 12, no. 1, pp. 61-97, 2018.

[45] T. S. Sun, "Evolution of agglomeration and its spatial structure with economic growth in three major metropolitan regions of China," Economic Geography, vol. 36, no. 5, pp. 63-70, 2016, in Chinese.

[46] Z. G. Li and K. Y. Shen, "Urban agglomeration spatial structure's effect on high-quality economic development," Social Sciences in Guangdong, vol. 37, no. 2, pp. 1-11, 2020, in Chinese.

[47] H. R. Zhang and B. Z. Yi, "Spatial structure and economic performance in Chinese urban agglomerations," Economic Review, vol. 1, pp. 42-47, 2012, in Chinese.

[48] L. Wang and Q. Gao, "The economic performance of urban cluster spatial structure in the Yangtze River middle reaches," Human Geography, vol. 33, no. 6, pp. 96-102, 2018, in Chinese.

[49] J. J. Tang, F. Y. Pang, and Z. J. Fan, "Spatial structure and regional economic efficiency in the process of urbanization: empirical study based on ASEAN eight countries," Southeast Asian Affairs, vol. 45, no. 4, pp. 84-104, 2018, in Chinese.

[50] E. J. Meijers, "Metropolitan labor productivity and urban spatial structure," Metropolitan Regions, Springer, Berlin, Heidelberg, pp. 141-166, 2013.

[51] F. Su and P. Y. Zhang, "Evolution characteristics of city-size distribution of urban agglomeration in middle and south liaoning Province," Scientia Geographica Sinica, vol. 30, no. 3, pp. 343-349, 2010, in Chinese.

[52] K. Futagami and Y. Ohkusa, "The quality ladder and product variety: larger economies may not grow faster," The Japanese Economic Review, vol. 54, no. 3, pp. 336-351, 2003.

[53] S. C. Ray and E. Desli, "Productivity growth, technical progress, and efficiency change in industrialized countries: comment," American Economic Review, vol. 87, no. 6, pp. 1033-1039, 1997.

[54] E. Grifell-Tatjé and C. A. K. Lovell, "A generalized Malmquist productivity index,” Top, vol. 7, no. 1, pp. 81-101, 1999.

[55] Beijing Municipal Bureau of Statistics, Beijing Statistical Yearbook (2007-2017), China Statistical Press, Beijing, China, 2008-2018.

[56] Beijing Municipal Bureau of Statistics, Beijing Area Statistical Yearbook (2007-2017), China Statistical Press, Beijing, China, 2008-2018.

[57] Hebei Municipal Bureau of Statistics, Hebei Statistical Yearbook (2007-2017), China Statistical Press, Beijing, China, 2008-2018.

[58] Tianjin Municipal Bureau of Statistics, Tianjin Statistical Yearbook (2007-2017), China Statistical Press, Beijing, China, 2008-2018.

[59] National Bureau of Statistics of China, "Department of urban socioeconomic investigation," China City Statistical Yearbook (2007-2017), China Statistical Press, Beijing, China, 2008-2018.

[60] National Bureau of Statistics of China, "Department of rural socio economic investigation, National Bureau of Statistics," China City Statistical Yearbook (County-Level) (2007-2017), China Statistical Press, Beijing, China, 2008-2018.

[61] G. P. Li and X. R. Luo, "Coordinated development between population and economy in the Beijing-Tianjin-Hebei region," Progress in Geography, vol. 36, no. 1, pp. 25-33, 2017, in Chinese. 
[62] X. L. Huang and J. G. Liu, "Regional economic efficiency and its influencing factors of beijing-tianjin-hebei metropolitans in China based on a heterogeneity stochastic frontier model," Chinese Geographical Science, vol. 30, no. 1, pp. 30-44, 2020.

[63] J. M. Li, W. Z. Zhang, T. S. Sun, and A. P. Zhang, "Characteristics of clustering and economic performance of urban agglomerations in China," Acta Geographica Sinica, vol. 69, no. 4, pp. 474-484, 2014, in Chinese.

[64] P. M. Romer, "Increasing returns and long-run growth," Journal Of Political Economy, vol. 94, no. 5, pp. 1002-1037, 1986.

[65] E.-h. Bah, J. C. Brada, and J. C. Brada, "Total factor productivity growth, structural change and convergence in the new members of the European union," Comparative Economic Studies, vol. 51, no. 4, pp. 421-446, 2009.

[66] M. Y. Li, Z. H. Zhang, and Z. Z. Hu, "Research on the contribution of land factors to economic growth: from the perspective of dual attributes of land resources and land assets," Urban Development Studies, vol. 25, no. 7, pp. 61-67, 2018, in Chinese.

[67] D. Herzer and J. Donaubauer, "The long-run effect of foreign direct investment on total factor productivity in developing countries: a panel cointegration analysis," Empirical Economics, vol. 54, no. 2, pp. 309-342, 2018.

[68] D. Feng, "Spatial and convergence study on science and education in-puts for Chinese," Science and Technology Management Research, vol. 36, no. 24, pp. 54-61, 2014, in Chinese.

[69] Q. M. Xu, C. G. Hu, and D. G. Liu, “The urban population agglomeration gradient and industrial structure's upgrading: a comparative research among China's Yangtze River Delta, Japan and South Korea," Chinese Journal of Population Science, vol. 126, no. 1, pp. 29-37, 2015, in Chinese.

[70] M. Brülhart and F. Sbergami, "Agglomeration and growth: cross-country evidence," Journal of Urban Economics, vol. 65, no. 1, pp. 48-63, 2009.

[71] G. P. Li and C. Y. Song, "Study on the strategy of optimizing the regional spatial structure of beijing, Tianjin and Hebei," Hebei Academic Journal, vol. 39, no. 1, pp. 137-145, 2019, in Chinese.

[72] J. V. Herderson, Community Development: The Effects of Growth and Uncertainty, American Economic Review, Pittsburgh, PA, USA, 1980.

[73] Y. Hou and T. S. Sun, "The economic performance of spatial structure of urban agglomeration in China: an Empirical Analysis Based on Panel Data," Inquiry Into Economic Issues, no. 2, pp. 80-88, 2016, in Chinese.

[74] C. Au and J. V. Henderson, "Are Chinese cities too small," The Review of Economic Studies, vol. 73, no. 6, pp. 549-576, 2006.

[75] B. He, X. L. Yuan, and L. Fang, "The synergistic development of urban scale expansion and efficiency improvement in China," Modern Economic Science, vol. 42, no. 1, pp. 120-134, 2020, in Chinese.

[76] J. Y. Hua and B. D. Sun, "Economic performance of the polycentric metropolitan spatial structure in China," Urban Problems, vol. 9, pp. 68-73, 2015, in Chinese.

[77] B. D. Sun, X. H. Wang, and Y. Y. Cai, "An empirical study on the economic performance of polycentric spatial structure of mega-cities in China," City Planning Review, vol. 39, no. 8, pp. 39-45, 2015, in Chinese.

[78] M. Fujita and H. Ogawa, "Multiple equilibria and structural transition of non-monocentric urban configurations," Regional Science and Urban Economics, vol. 12, no. 2, pp. 161196, 1982.
[79] B. Lee, Urban Spatial Structure, Commuting, and Growth in US Metropolitan Areas, pp. 130-148, University of Southern California, Los Angeles, CA, USA, 2006.

[80] B. D. Sun and S. Ding, "Progress and implications for polycentric spatial structure's effect on economic performance," Scientia Geographica Sinica, vol. 37, no. 1, pp. 64-71, 2017, in Chinese.

[81] T. S. Sun, G. P. Li, and M. H. Li, "Concentration and decentralization of population in the beijing-tianjin-hebei metropolitan region and its determinants: a regional density function approach," Acta Geographica Sinica, vol. 64, no. 8, pp. 956-966, 2009, in Chinese.

[82] X. L. Fan and L. X. Huang, "The characteristics of city size distribution in Beijing-Tianjin-Hebei urban agglomeration," Journal of Arid Land Resources and Environment, vol. 29, no. 9, pp. 13-20, 2015, in Chinese.

[83] Q. M. Xi and G. P. Li, "The countermeasures study on the balanced development of population in beijing-tianjin-hebei," China Business and Market, vol. 29, no. 4, pp. 77-82, 2015, in Chinese.

[84] S. Vincenzo, "Quality of human and physical capital and technological gaps across Italian regions," Regional Studies, vol. 41, no. 5, pp. 585-599, 2007.

[85] Z. H. Dong, "Research on the interaction between human capital and economic growth-an empirical analysis based on China's human capital index," Macroeconomics, vol. 4, pp. 88-98, 2017, in Chinese.

[86] F. Cai, Y. F. Lin, X. S. Zhang, L. Zhu, and L. Zheng, "Years of reform and opening up and China's economic development," Economic Perspectives, vol. 8, pp. 4-17, 2018, in Chinese.

[87] S. Jin, J. Yang, E. Wang, and J. Liu, "The influence of highspeed rail on ice-snow tourism in northeastern China," Tourism Management, vol. 78, p. 104070, 2020.

[88] C. Li, K. Wu, and X. Gao, "Manufacturing industry agglomeration and spatial clustering: evidence from Hebei Province, China," Environment, Development and Sustainability, vol. 22, no. 4, pp. 2941-2965, 2019.

[89] C. F. He, X. D. Zhu, Y. H. Kong, and W. Li, “Agglomeration economy, incentive policy and the spatial pattern of Chinese computer manufacturing industry: a case study based on export data," Scientia Geographica Sinica, vol. 38, no. 10, pp. 1579-1588, 2018, in Chinese.

[90] X. Q. Ping, “The relationship between market and government in the industrial structure adjustment," Research on Economics and Management, vol. 37, no. 5, pp. 3-7, 2016, in Chinese.

[91] J. Feng and Y. X. Zhou, "The social spatial structure of Beijing Metropolitan Area and its evolution: 1982-2000," Geographical Research, vol. 22, no. 4, pp. 465-483, 2003, in Chinese.

[92] K. Rupika and S. Chandan, "Do infrastructure and quality of governance matter for manufacturing productivity? Empirical evidence from the Indian states," Journal of Economic Studies, vol. 45, no. 4, pp. 829-854, 2018.

[93] Y. J. Ren, C. X. Wang, and C. Yu, "Research on spatial spillover effects of green total factor productivity in China," Soft Science, vol. 33, no. 4, pp. 40-43, 2019, in Chinese. 